\title{
SPECIFIC HEAT OF SUPERHEATED AMMONIA VAPOR
}

\author{
N. S. Osborne, H. F. Stimson, T. S. Sligh, Jr., and C. S. Cragoe
}

\section{ABSTRACT}

Measurements of the specific heat at constant pressure of superheated ammonia vapor were made within the range of temperature and pressure ordinarily used in refrigeration, namely, in the temperature interval -15 to $+150^{\circ} \mathrm{C}$. and at various pressures ranging from 0.5 to 20 atmospheres. Incidentally a few measurements of the Joule-Thomson effect were made in order to evaluate certain small correction terms.

The method employed is a familiar one in calorimetry, that of continuous fiow combined with electric heating of the vapor. The principle of this method is to observe the rise in temperature produced by a measured electric power added as beat to a steady stream of vapor flowing through the instrument at a measured rate.

A flow calorimeter, which was developed for the particular purpose of making these measurements on ammonia, is briefly described. Refinements were incorporated into the calorimetric apparatus to limit size and thermal capacity, to secure sensitivity, to avoid thermal leakage, and to control experimental conditions which affect steadiness.

\section{CONTENTS}

II. General description of method and apparatus.

1. Method

2. Arrangement of apparatus. 67

3. Description of calorimeter.

4. Thermoregulated baths.............. 73

5. Regulation of rate of flow

6. Means for insuring dryness of vapor........ 74

7. Accessory apparatus._._. 75

III. Theory of method

1. Notation and definitions of quantities_._.......... 77

2. Determination of $C_{D} \ldots$

3. Determination of Joule-Thomson coefficient....... 80

IV. Material_........ 81

V. Experimental details_..._.

1. Calibration of apparatus.

2. Experimental procedure in determinations of $C_{\mathrm{p}} \ldots$

3. Experimental procedure in determination of $\mu_{\ldots} \ldots$

4. Thermal leakage................... 86

5. Preliminary experiments on $C_{\mathrm{p}} \ldots$

6. Experiments near saturation... 93

VI. Results of measurements

1. Calorimetric data

$\begin{array}{rr}\text { 2. Computation of results } & 100 \\ \text { VII. Form of empirical equation, } C_{\mathrm{p}}=f(p, \theta) \ldots \ldots & 101\end{array}$

VIII. Discussion of results

IX. Previous determinations

X. Summary

XI. Appendix: Table of $C_{\mathrm{p}}$ 


\section{INTRODUCTION}

This series of measurements of the specific heat of superheated ammonia vapor is one of a group of experimental investigations of this fluid. The purpose of the whole experimental project has been to provide adequate data for tables of thermodynamic properties of ammonia (already published ${ }^{1}$ ) suitable for use in refrigeration engineering.

The results of the calorimetric measurements on superheated ammonia vapor have been expressed as values of the specific heat at constant pressure as a convenient intermediate step between the experiments and the final formulation of the properties of the vapor.

The aim has been to obtain calorimetric data for the superheated vapor comparable in accuracy with the results of the other experimental measurements of the group, so that consistent tables might be formulated which would agree throughout with the experimental data.

\section{GENERAL DESCRIPTION OF METHOD AND APPARATUS}

\section{METHOD}

The method employed in these measurements of the specific heat ${ }^{2}$ is that known as the continuous-flow electric method. This method was used by Callendar and Barnes ${ }^{3}$ for measurements of the specific heat of liquids. It has also been used successfully for the measurement of the specific heat of gases by a number of experimenters, notably Swann, ${ }^{4}$ Scheel and Heuse, ${ }^{5}$ Holborn and Jakob, ${ }^{6}$ and Knoblauch and his associates. ${ }^{7}$

Measurements of the specific heat of gases are, in general, more difficult than of solias and liquids because larger volumes of gas must be subjected to the experimental process in order to have heat quantities large enough for accurate measurement. The flow method is particularly suited to calorimetry of superheated vapor because this method allows a large quantity of the vapor to be subjected to experiment in a given time in a relatively small apparatus. The heat capacity of the calorimeter does not enter as a direct element of the measurement, but does affect the time required to reach a steady state.

The principle of the electric-flow method is simple. The procedure is to observe the rise in temperature produced by a measured electric

\footnotetext{
1 B. S. Circular No. 142, 1st edition; 1923.

2 The term specific heat as used in this paper will refer to the specific heat at constant pressure; that is, the heat required per unit mass per degree to change the temperature of the vapor when kept at constant pressure.

${ }^{3}$ Brit. Assoc. Report, p. 552; 1897. Phil. Trans., 199 A, p. 55; 1902.

Roy. Soc. Phil. Trans., 210, p. 199; 1910.

5 Ann. d. Phys., 37, p. 79, 1912; 40, p. 473, 1913; 59, p. 86, 1919.

6 Zs. des. Verein. Deutsch. Ing., 58, p. 1429, 1914; 61. p. 146, 1917; Phy. Zs., 6, p. 801, 1905.

${ }^{7}$ Zs. des. Verein Deutsch. Ing., 51, p. 81, 1907; 55, p. 665, 1911;59, p. 376, 1915;66, p. 418, 1922.
} 


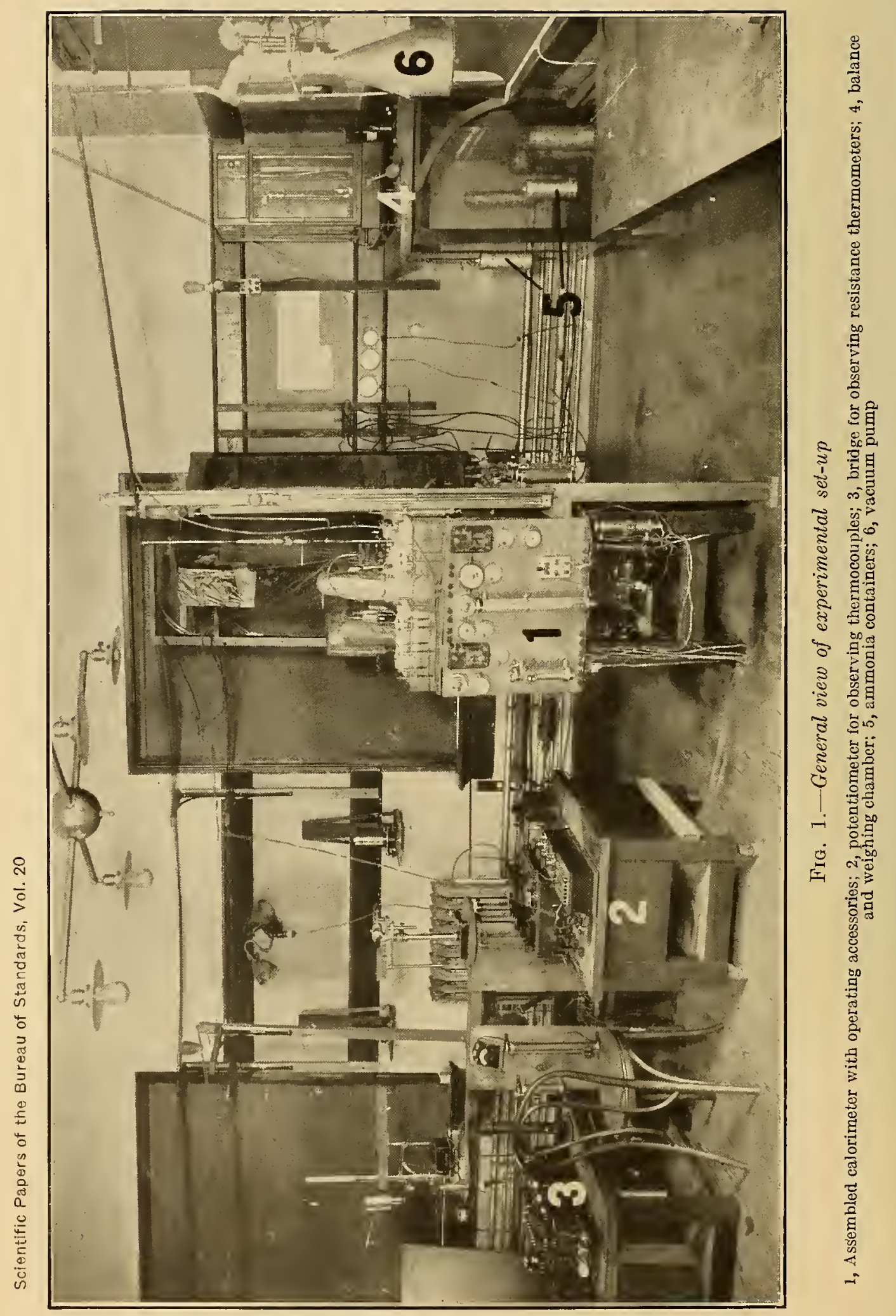


power added as heat to a stream of fluid flowing through the calorimeter at a steady measured rate. In the apparatus described here, the rate of flow, when steady, is measured by condensing and weighing the ammonia vapor discharged from the calorimeter in a known interval of time. The electric power input is obtained from measurements of the potential drop across and the current flowing through the heater. The rise in temperature of the vapor is measured by two platinum resistance thermometers in the vapor stream, one before and one after the electric heater. The accuracy of the specific heat determinations depends to a large extent upon the constancy of these observed quantities during an experiment, and the accuracy with which they are measured. One of the important advantages of this method is that effects which could lead to constant or systematic errors may be eliminated by varying these three principal observed quantities through a series of experiments, and noting the effect on the results. Another important advantage is that the steady state required by the method favors accuracy of the observations because they may be made deliberately.

Other quantities which enter into the determinations of the specific heat as small corrections are heat leakage and the effect of pressure drop. The evaluation of these quantities is discussed in later sections of this paper.

\section{ARRANGEMENT OF APPARATUS}

A general view of the apparatus as actually used is shown in Figure 1. A diagram of the arrangement of the important parts is shown in Figure 2. The three large heavily dotted squares, $A, B$, and $C$, represent stirred, thermally controlled liquid baths. The parts within any one of these squares are supposed to be at or near that particular bath temperature. The first or "boiler bath," $A$, furnishes heat to evaporate the ammonia in the reservoirs, $D$, which are immersed in the liquid. From these reservoirs the vapor passes through three needle valves, $E, F$, and $K$, in series, where the pressure is reduced and regulated. Thus far the path of the vapor has been in a region controlled to a uniform temperature. From here the path of the vapor next leads into the second or calorimeter bath, $B$, which is a region of uniform temperature surrounding the calorimeter. Here the vapor first passes through a length of tube to bring it to the bath temperature, and is then led into the calorimeter itself. Within the calorimeter the vapor continues successively through thermometer cell, $T_{1}$, heater cell, $H$, and thermometer cell, $T_{2}$. From the calorimeter the path of the vapor leads through the throttle valve, $J$, through one or more control orifices, $L$, in parallel, and there leaves the calorimeter bath and enters the third or condenser hath, $C$. Here the ammonia is led into one of the reservoirs, $N$, which are cooled by the bath in order to condense and collect the ammonia. 
The cell, $H$, contains the electric heater, by means of which measured electric power is added to the stream of vapor. Each of the cells, $T_{1}$ and $T_{2}$, contains a resistance thermometer to measure the temperature of the vapor, one before and one after the addition of the heat. Each of these thermometer cells has a connection to the pressure-measuring apparatus which enables the pressure to be observed simultaneously with the temperature. Two gauges are

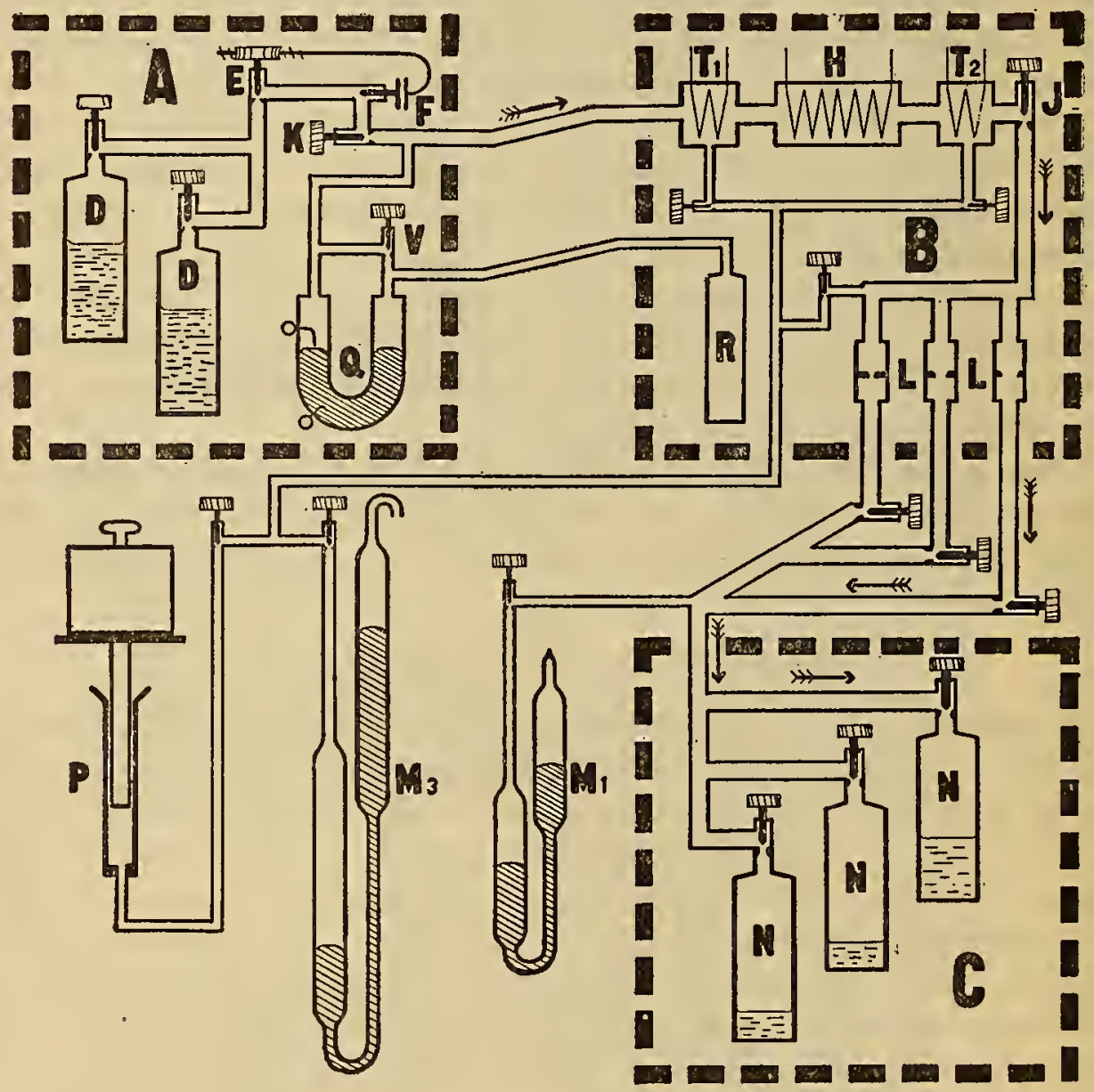

FIG. 2.-Diagram of general arrangement

$A$, boiler bath. $B$, calorimeter bath. $C$, condenser bath. $D$, reservoirs used as evaporators. $E, F$, and $K$, valves for regulating rate of flow: $H$, heater cell. $T_{1}$ and $T_{2}$, thermometer cells. $J$, reducing valve. $L$, flow control orifices. $N$, reservoirs used as condensers. $M_{1}$, one-atmosphere mercury manometer. $M_{3}$, three-atmosphere mercury manometer. $P$, piston gauge. $Q$, manometer for actuating pressure regulator. $V$, by-pass valve. $R$, reservoir for reference pressure.

provided, one a mercury gauge, $M_{3}$, for pressures up to 3 atmospheres, and the other a piston gauge, $P$, for higher pressures up to 100 atmospheres. The pressure just before the orifices, $L$, may also be observed by these gauges. The condenser line is provided with a mercury manometer, $M_{1}$, for pressures under 1 atmosphere.

The mercury manometer, $Q$, the reference pressure reservoir, $R$, and the valves, $V, E$, and $F$, are used in the automatic regulation of 
pressure before the calorimeter. This pressure regulation combined with the action of the orifice control, $L$, regulates the flow. Constancy of the flow is a vital requirement of the continuous-flow method of calorimetry.

\section{DESCRIPTION OF CALORIMETER}

Although the term "calorimeter" might be applied to the entire group of apparatus used to measure the heat in an experimental process, this term will, for convenience, be used here to denote that portion of the apparatus where the experimental process occurs, the place where this process is isolated from external influences so that it may be accurately controlled and observed. The calorimeter and the more important parts of the equipment for its operation will be described in greater detail elsewhere. ${ }^{8}$

The calorimeter was designed and constructed primarily for measuring the specific heat of ammonia vapor at temperatures up to $150^{\circ} \mathrm{C}$. and at pressures up to 20 atmospheres. To meet the requirements of the ammonia research it was desirable to combine into one instrument a number of features which are of obvious advantage, but which are not usually all found in a flow calorimeter. Among these features are: Utility over a wide range of temperature and pressure; small size and heat capacity; small thermal leakage; and means for accurately observing temperatures and heat added.

The function of this calorimeter is to provide a system within which we may account for the amount of vapor passing through, the state of the vapor, and the amount of energy added. The predominating influence in the design has been the development of means for conserving the heat added to the system. Our inability to avoid unmeasured leakage of heat limits the accuracy of determining the net amount of heat added, which is a direct factor of the result.

In this "calorimeter system," which is that part of the calorimeter in good thermal contact with the vapor stream between and including the two thermometer cells, the principal ways for loss or gain of heat other than through the electric heater are by (1) conduction, either along the tubes carrying the ammonia, the supports of the system, or the electric lead wires; (2) gaseous conduction and convcction; (3) radiation. The second of these was the simplest to control, for it was found that the exhaustion of the space surrounding the calorimeter system to a pressure of $0.001 \mathrm{~mm}$ of mercury or less would reduce this element of the thermal leakage to a negligible amount. Heat conduction along the solid connections was controlled by first making the thermal resistance of these connections large and, second, by leading them away from the system to points outside kept at the same temperatures. Transfer of heat by radia-

\footnotetext{
- B S. Sci. Paper on A Flow Calorimeter for Specific Heats of Gases.
} 
tion was controlled by surrounding the system with metal guards maintained at temperatures nearly identical with the temperatures of the exposed parts of the system within. To make this possible a configuration of the system was devised which would keep practially all the exposed surface approximately at either the initial or the final temperature of the vapor. Only two protecting guards were then necessary, one at each temperature. One of these was kept at the initial temperature by the incoming gas stream and the other was controlled by an auxiliary electric heater and regulated by the observer to maintain that guard surface close to the temperature of the system within. The manner of accomplishing this result will appear as we describe the construction.

An idea of the actual figure of the calorimeter may be obtained from Figure 3. The important elements shown diagramatically in Figure 2 may be recognized here, namely, first thermometer cell, $T_{1}$, heater cell, $H$, and second thermometer cell, $T_{2}$. The figure of the channel in which the vapor is led along to the regions where its state is altered and observed is important. To get a clear idea of the thermal shielding we may again follow the path of the vapor through this vital portion of the instrument.

Before entering the calorimeter the vapor passes through a coil of tubing immersed in the bath to bring it to a definite temperature. It is important that on entering the calorimeter the vapor and the parts of the calorimeter in contact with it shall be near equilibrium with the temperature of the bath. To this end the vapor next passes through the coil, $B$, which is soldered to the calorimeter casing or envelope, and is bathed by the liquid. Thence the vapor tube passes through the envelope and across the vacuum space to the copper guard, $G_{1}$. The tube is soldered to this guard, winding spirally upward and then back to the lower end, where it passes inside the guard, $G_{1}$, to the entrance of thermometer cell, $T_{1}$. It is intended that the guard, $G_{1}$, should thus be kept automatically as nearly as possible at the temperature of the vapor as it enters the thermometer cell so that the initial temperature of the vapor may be correctly indicated. The connection, $P_{1}$, is for determining the initial pressure of the vapor. In passing from the thermometer cell to the heater cell the vapor is led through a coil of German silver tube bearing the copper shield, $S_{1}$, and thence on through the straight inlet tube into the heater cell. This is the place where the vapor enters the region where it is heated. Here the system is narrowed or necked down to the bare essentials to transmit the vapor across, and the shields are brought as close to the vapor tube and to each other as mechanical technique will permit, so that little area may be left exposed to radiation at an intermediate and uncontrolled temperature. The function of this "neck" is to confine, within clearly defined limits, the flow not 


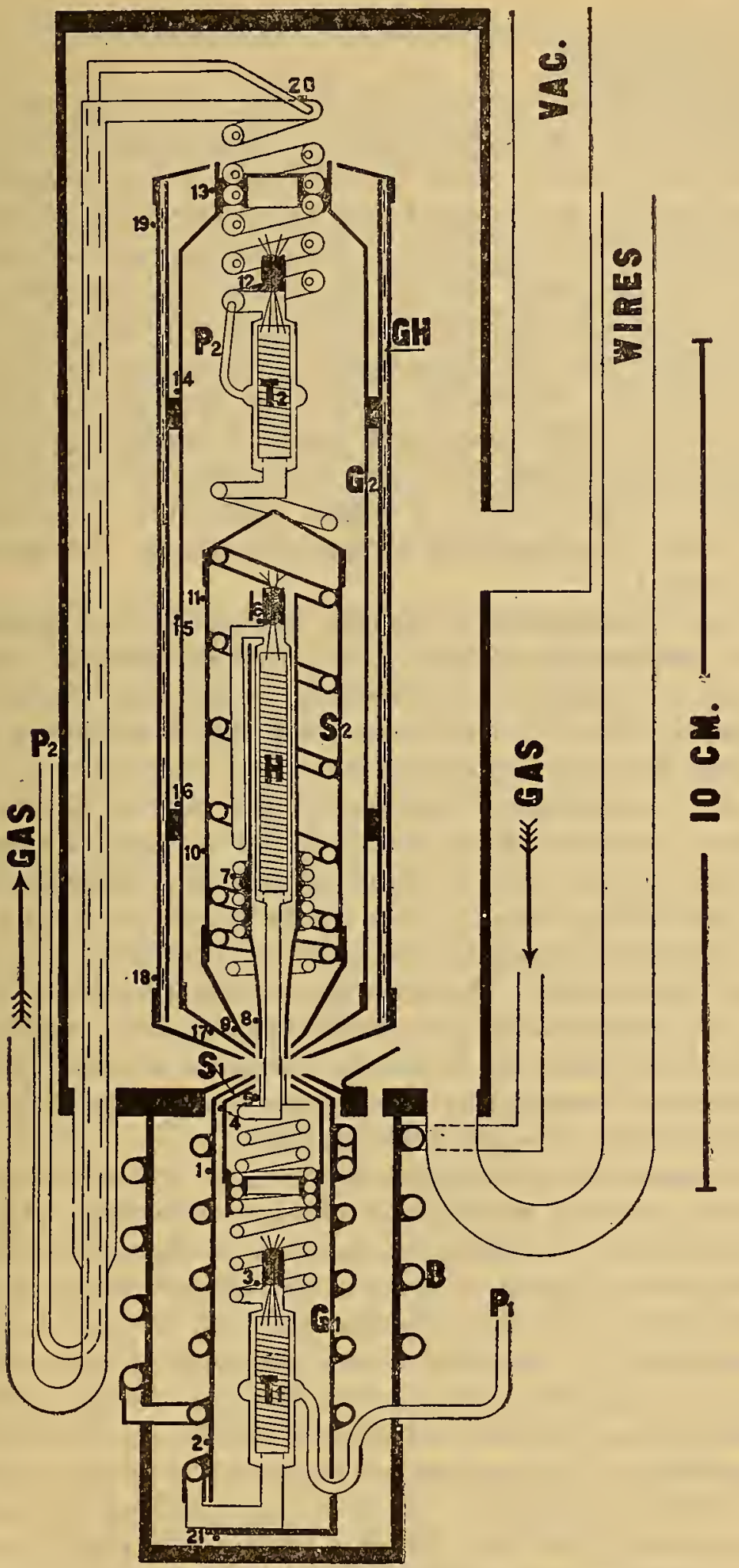

FIG. 3.-Sectional drawing of calorimeter system (full scale)

Copper in heavy lines; german silver in light lines; location of thermojunctions indicated by numbered dots. $B$, helix soldered to envelope. $H$, heater cell. $T_{1}$ and $T_{2}$, thermometers. $S_{1}$ and $S_{2}$, isothermal shields for conserving heat in calorimeter system. $G_{1}$ and $G_{2}$, isothermal guards for protecting calorimeter system from thermal leakage. $P_{1}$ and $P_{2}$, pressure connections to thermometer cells. $G H$, heater for guard $G_{2}$. $V A C$, connection to vacuum pump $13129^{\circ}-25 \dagger-2$ 
only of the ammonia vapor, but also of the quantities of heat with which we are dealing.

The vapor enters the heater cell, $H$, and receives the energy which is added through the electric heater. The parts through which the vapor next flows tend to annul the differences in temperature between the vapor and its flow channel, and to provide temperature control of shielding surfaces to protect the inclosed parts against gain or loss of heat. At the upper end of the heater cell the channel turns abruptly to the side and again downward and then winds spirally for five turns about the cylindrical copper shell which incloses the heater cell itself. The vapor is then led through the coiled tube soldered to the cylindrical copper shield, $S_{2}$, so that the shield and vapor tend to approach the same temperature; that is, the final temperature of the vapor. A single spiral turn of german-silver tubing carries this isothermal stream of vapor to the second thermometer cell, $T_{2}$.

The vapor then passes on through the six turns of german-silver tubing to the straight channel which, turning abruptly, then leads down and out through the wall of the casing into the bath again. The pressure tube, $P_{2}$, is led out from the thermometer cell, $T_{2}$, through the flow tube for thermal reasons.

The guard, $G_{2}$, incloses virtually all the exposed portion of the calorimeter system which is at the higher or final temperature of the ammonia vapor. This guard is maintained at this same temperature by an electric heater. This heater is located in the annular cylindrical space between two concentric copper shells and is called the guard heater, $G H$. Thermocouples on the guard, on the shield, and on the thermometer cell permit the relative temperatures of these parts to be observed, and these indications are used for gauging the regulation of temperature of the guard so as to annul the thermal leakage to or from the calorimeter system.

Each thermometer coil contained about $54 \mathrm{~cm}$ of platinum wire $0.05 \mathrm{~mm}$ in diameter wound on a notched mica strip, about seven turns to the $\mathrm{mm}$. The potential terminal arrangement of leads was used and the four platinum leads from each thermometer were brought out of the upper end of the thermometer cell through a glass seal. The heater coil, $H$, contained about $100 \mathrm{ohms}$ of bare calido wire wound on a mica strip very much like the thermometers. The thermometers had fundamental intervals of 10.8 and $10.7 \mathrm{ohms}$, so that a sensitivity of the temperature measuring apparatus to $0.001^{\circ} \mathrm{C}$. was not difficult to secure. As to the type of lead connections to the thermometers and the manner of their use, it might be inferred that the use of a pair of differentially connected Callendar type thermometers would have been appropriate, as such an arrangement would have required only a single reading of resistance to evaluate 
the temperature rise instead of the four readings necessary with the arrangement used. Nevertheless, the choice of the potential terminal type of thermometer was made deliberately for the purpose of obtaining increased accuracy, as other considerations outweighed the one mentioned above.

The size or scale upon which the apparatus has been built has affected both its utility and its construction. In order to avoid useless bulk and thermal capacity which would require either preparation of unnecessarily large amounts of purified ammonia, or else sacrifice either time or accuracy in operation, some effort was made to keep the proportions small.

It had been found by experiment that the metals used in the construction of the calorimeter were not attacked by pure anhydrous ammonia.

\section{THERMOREGULATED BATHS}

Considerable attention was devoted to the design and construction of temperature control baths, to simplify construction, economize space, and promote reliability of operation. Three baths were used which were similar in general construction, each having modifications to adapt it to the performance of a particular service. Their shape favored the assembling of the calorimetric equipment upon a table in a compact group, the important elements of which were easily accessible, either for manipulation or observation.

Each bath was provided with a control unit which included a screw propeller, a refrigerating coil using carbon dioxide, an electric heating coil, and a thermoregulator, actuated by expansion of a confined liquid. These parts were assembled in a tubular housing which stood vertically in one corner and the rest of the space in the bath was available for installing such parts of the apparatus as required temperature control. The method of control was to overcool somewhat by a proper setting of the carbon dioxide throttle valve, and compensate the overcooling by electric heating, so controlled by an automatic regulating device as to keep the fluctuations of temperature within the desired limits. Extremely fine regulation was necessary only in the calorimeter bath, and it was found possible to control this bath so that no change of more than $0.001^{\circ} \mathrm{C}$. could be observed over a period of 30 minutes or longer. The reliability of operation of this thermal control and the relief of the operator from this care was a factor contributing to the character of the final results.

\section{REGULATION OF RATE OF FLOW}

The rate of flow of the vapor is regulated by controlling the pressure in the line before and after the calorimeter. Use is made of the principle that gaseous flow through an orifice is practically inde- 
pendent of the low side or back pressure, provided this pressure is less than a certain fraction of the high side or fore pressure. In applying this principle the ammonia lines are so arranged that the vapor after leaving the calorimeter is discharged into the condenser line through one or more orifices in parallel and the pressure thus reduced to a sufficiently low value. In the experiments with ammonia it was found that when the back pressure in the condenser line was kept less than 0.35 of the fore pressure on the orifices the flow was sensibly dependent only on the pressure in the calorimeter. In consequence, only a rough control on the condenser line pressure is needed, and having this the close regulation of flow results from control of the pressure in the calorimeter. Since constant flow is one of the essentials to accuracy, the device for regulating the calorimeter pressure is a vital part of the apparatus.

The pressure regulator is automatic and operates in a manner similar to the action of a familiar type of temperature regulator. One arm of the manometer, $Q$ (fig. 2); is connected to the flow line ahead of the calorimeter and the other to a reservoir, $R$, which is immersed in the calorimeter bath for constancy of temperature. The pressure in this reservoir may be adjusted to any chosen reference value by transmitting ammonia through the by-pass valve, $V$. For automatic control the by-pass valve is closed, and then the pressure in the calorimeter line is balanced against the reference pressure. Departures of the line pressure from this reference value cause the mercury in the manometer to make or break electric contact with the platinum wires sealed through the glass. Making or breaking this contact controls through a relay the direction of rotation of an electric motor, which in turn through a mechanism controls the settings of valves, $E$ and $F$.

The operation of the regulating device resulted in a periodic fluctuation of the line pressure, the amplitude and period of which were subject to the control of the operator. It was usually found possible to adjust the cycle of operation to a period of from 5 to 10 seconds and a fluctuation of not more than $1 \mathrm{~mm}$ of mercury. The device was so sensitive to fortuitous influences that it could not be left unattended for long without danger of spoiling an experiment, but with due vigilance it could be kept functioning indefinitely.

A detailed description, together with photographs of this regulating device, is given elsewhere. ${ }^{9}$

\section{MEANS FOR INSURING DRYNESS OF VAPOR}

Besides the provision made for observing the quantities from which the specific heat may be derived, there is another factor no less vital to accurate results than any of the refinements in equipment or operation. This factor is the quality of the vapor. Of course, if

? See footnote 8, p. 69. 
the vapor is truly superheated and the state is truly indicated by the observed temperatures and pressures, no question of quality would be encountered except at the saturation limit. But if on the contrary a liquid spray or fog were to be formed at any place in the stream before it entered the calorimeter, and if these mechanically entrained droplets should be swept on into the calorimeter, the resulting value of the specific heat would evidently be in error on account of the heat required to evaporate this spray in the calorimeter.

The measures taken to avoid this occurrence are for the most part automatic in operation. The evaporation took place at a pressure from three to eight atmospheres higher than the working pressure in the calorimeter. The stream of vapor coming from the reservoirs in the boiler bath, $A$ (fig. 2), passed to the needle valve, $E$, in the regulating train. It was then throttled successively in each of the three valves, $E, F$, and $K$. Each of these three valve bodies was in very good thermal connection with the boiler bath through a copper bracket soldered to the copper wall of the tank. This connection would tend to supply heat to the stream of ammonia at each valve to compensate for any cooling caused by the throttling. Besides this first approximation to isothermal throttling, further opportunity was given the ammonia stream to reheat between valves, $F$ and $K$, and again after valve, $K$, by soldering a length of the flow tube directly to the wall of the tank. In operation the total reduction in pressure in this regulating train of valves was usually from three to eight atmospheres. This process of isothermal throttling in three stages would tend to eliminate any traces of liquid which might otherwise have been swept through.

Besides these precautionary measures to guard against wetness or nonuniformity in the ammonia stream entering the calorimeter, there was an effective means of test which would disclose any sensible effect produced on the result by wetness. This test was the repetition of experiments with different rates of flow. The principle of this test was that if spray or fog were entrained in the process of evaporation, the degree of wetness would depend upon the rapidity of the evaporation, and the elimination of entrained liquid would be the more perfect the slower the flow. Agreement of the resulting values of specific heat for different rates of flow assures us of the proper dryness of the vapor.

\section{ACCESSORY APPARATUS}

Accessory apparatus, such as vacuum pumps, McLeod gauges, pressure gauges, potentiometers, thermometer bridge, and balance, although essential parts of the experimental set-up, are so familiar and well described elsewhere that they need only be mentioned briefly here. Two vacuum pumps and McLeod gauges were used. 
One set was used to evacuate the calorimeter envelope, and the other to evacuate the flow line for the connections to the condenser, as desired. The vacuum pumps are of the mercury-vapor type as designed and described by Stimson. ${ }^{10}$

Two pressure gauges were installed for measuring the pressure of the ammonia vapor during determinations. For pressures up to three atmospheres an ordinary open-end mercury-in-glass manometer was used, supplemented by a barometer. For higher pressures an oil-sealed, dead-weight, rotating piston gauge was used.

A Leeds \& Northrup type $\mathrm{K}$ slide wire potentiometer was used for the power measurements, and a Wolff-Disselhorst potentiometer for the thermocouple readings. For the resistance thermometer readings a Mueller type Wheatstone bridge ${ }^{11}$ with shunt decades was used.

The steel containers with ammonia were weighed on a Rueprecht balance rated at $2 \mathrm{~kg}$ capacity. The balance was mounted on a shelf and was provided with suspensions which extended from the scale pans down into an inclosed weighing chamber. (See fig. 1.)

The time signals used to measure the duration of flow in the determinations of the rate of flow were controlled by a Riefler clock with electric contacts.

About 40 valves were used on the closed ammonia system, which must needs be tight for trustworthy experimental work. Considerable study was deroted to the improvement of a type of small needle valve which had already been developed at this bureau for nice experimental work with fluids. Improvement in workmanship was found to be the most important element in attaining reliability. The thread, the stainless-steel conical tip, and the stuffing-box bearing of the stem were all ground or lapped and polished to reduce friction and avoid wear. A paraffin filled fine-grained leather stuffing held between two accurately fitted brass retainers was kept under a steady pressure by a stiff spring. Most of the valves were provided with extended stems of german-silver tubing so that the stuffing boxes could be at room temperature, and the seats at the temperature of the bath. The performance of all the valves was found to be entirely satisfactory, and their dependability both for vacuum and pressure contributed much to the reliability of the experimental results.

\section{THEORY OF METHOD}

In the preceding section the method of procedure in the experiments and the arrangement of the apparatus have been outlined. Consideration will now be given to the method of computation of the specific heat at constant pressure from the observed data. For this

10 Jour. Wash. Acad. of Sci. 7, p. 477; 1917.

11 B. S. Bulletin 13, p. 547; 1916 (Sci. Paper No. 288). 
purpose we shall assume that the following quantities have been measured after the calorimeter has reached a steady state:

1. Current in electric heating coil.

2. Potential drop across heating coil.

3. Rate of flow of vapor through calorimeter.

4. Initial and final temperatures of vapor.

5. Initial and final pressures of vapor.

6. Temperature difference between heater shield and guard.

Given these data and some additional data for evaluating the corrections for thermal leakage and Joule-Thompson effect, our problem is to obtain an expression for the specific heat at constant pressure for a definite temperature and pressure.

\section{NOTATION AND DEFINITIONS OF QUANTITIES}

1, $2=$ designations for initial and final states, respectively.

$I=$ heating current, in amperes.

$E=$ potential differences, in volts, across heating coil.

$q=$ general symbol for heat added per unit mass.

$\Delta q=$ heat added per unit mass for the change from state 1 to state 2.

$F=$ rate of flow of vapor, in grams per second.

$v=$ specific volume of vapor.

$p=$ pressure.

$\theta=$ temperature.

$\Delta p=p_{2}-p_{1}=$ pressure change from state 1 to state 2. (Since there is a drop in pressure, $\Delta p$ is always negative.)

$\Delta \theta=\theta_{2}-\theta_{1}=$ temperature change from state 1 to state 2 . (In $C_{p}$ experiments $\Delta \theta$ is positive, in Joule-Thomson experiments $\Delta \theta$ is negative.)

$p_{m}=\frac{p_{1}+p_{2}}{2}=$ mean pressure.

$\theta_{m}=\frac{\theta_{1}+\theta_{2}}{2}=$ mean temperature.

$\epsilon=$ internal energy per unit mass.

$H=\epsilon+p v=$ heat content per unit mass.

$\mu=\left(\frac{\partial \theta}{\partial p}\right)_{\Pi}=$ Joule-Thomson coefficient.

$C_{\mathrm{p}}=$ specific heat at constant pressure.

$X=$ heat added per second by thermal leakage in any experiment.

$N=$ indicated excess of temperature of guard over that of heater shield, expressed in microvolts.

$x=$ coefficient of thermal leakage, in watts per microvolt. 


\section{DETERMINATION OF $C_{D}$}

Let us consider a fluid, in this case ammonia vapor, flowing steadily along a channel $T_{1} H T_{2}$ (fig. 4), in which $T_{1}^{\prime}$ and $T_{2}^{\prime}$ represent thermometer cells and $H$ represents a heater cell. Let $S_{1}$ and $S_{2}$ be two sections of the channel, the entrance and exit sections. Let $p_{1} v_{1} \theta_{1} \epsilon_{1}$ be, respectively, the pressure, specific volume, temperature, and internal energy of the vapor as it passes the entrance section and let $p_{2} v_{2} \theta_{2} \epsilon_{2}$ be the corresponding quantities at the exit section. In these experiments the change of potential energy due to change of level and the change of kinetic energy due to change of speed are, taken together, always less than 0.01 per cent of the work equivalent. of the heat added; and since this amount is negligible we may apply the first law of thermodynamics as if the fluid were at rest.

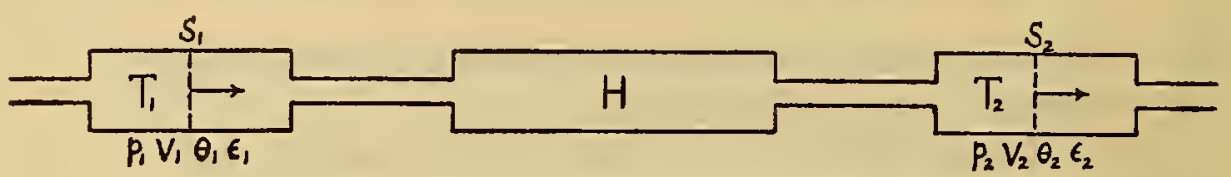

FIG. 4.-Diagram of calorimeter system

Since the vapor enters $S_{1}$ at the pressure $p_{1}$ and issues from $S_{2}$ at the pressure $p_{2}$ the net external work done by each gram in passing through the apparatus from the state 1 to the state 2 is $\left(p_{2} v_{2}-p_{1} v_{1}\right)$. The sum of this quantity of work and the simultaneous increase of internal energy $\left(\epsilon_{2}-\epsilon_{1}\right)$ is equal, by the first law, to the quantity of heat added so that we have

$$
\Delta q=p_{2} v_{2}-p_{1} v_{1}+\epsilon_{2}-\epsilon_{1}
$$

all quantities of heat, work, and internal energy being expressed in the same units. But since $H=\epsilon+p v$ we have by substitution

$$
\Delta q=H_{2}-H_{1}
$$

This equation shows that for the flow process under consideration the quantity of heat supplied is equal to the change in heat content. A similar reasoning applied to a constant pressure process also shows that the quantity of heat supplied is equal to the change in heat content so that

$$
C_{\mathbf{p}}=\left(\frac{\partial H}{\partial \theta}\right)_{\mathbf{p}}
$$

Inasmuch as the change of heat content $H_{2}-H_{1}$, depends only on the initial and final states, it would have been the same if the fall in pressure and the rise in temperature had occurred in two separate steps instead of simultaneously. Let us consider such a process in which the first step consists of an isothermal expansion of the vapor from $p_{1}$ to $p_{2}$ at the initial temperature $\theta_{1}$ and the second 
consists of a heating from $\theta_{1}$ to $\theta_{2}$ at the pressure $p_{2}$. The changes in heat content for these two steps are

$$
\int_{p_{1}}^{p_{2}}\left(\frac{\partial H}{\partial p}\right)_{\theta_{1}} d p \text { and } \int_{\theta_{1}}^{\theta_{2}}\left(\frac{\partial H}{\partial \theta}\right)_{p_{2}} d \theta
$$

respectively, and the total change in heat content in passing from state 1 to state 2 is

$$
H_{2}-H_{1}=\int_{p_{1}}^{p_{2}}\left(\frac{\partial H}{\partial p}\right)_{\theta_{1}} d p+\int_{\theta_{1}}^{\theta_{2}}\left(\frac{\partial H}{\partial \theta}\right)_{p_{1}} d \theta
$$

Making use of the general relation

$$
\left(\frac{\partial H}{\partial p}\right)_{\theta}=-\left(\frac{\partial H}{\partial \theta}\right)_{p}\left(\frac{\partial \theta}{\partial p}\right)_{H}
$$

and substituting $\mu$ for $\left(\frac{\partial \theta}{\partial p}\right)_{H}, C_{p}$ for $\left(\frac{\partial H}{\partial \theta}\right)_{p}$, and $\Delta q$ for $H_{2}-H_{1}$, equation (3) may be written in the form

$$
\int_{\theta_{1}}^{\theta_{2}}\left[C_{\mathbf{p}}\right]_{p_{2}} d \theta=\Delta q+\int_{p_{1}}^{p_{2}}\left[\mu C_{\mathbf{p}}\right]_{\theta_{1}} d p
$$

The last term in this equation represents the correction for pressure drop. Since the pressure drop in these experiments is small and since the magnitude of this correction is small in comparison with the heat added, $\Delta q$, it is sufficiently accurate for our purpose to assume that $\left[\mu C_{\mathbf{p}}\right]_{\theta_{1}}$ varies linearly with pressure, and write

$$
\int_{\theta_{1}}^{\theta_{2}}\left[C_{\mathrm{p}}\right]_{p_{2}} d \theta=\Delta q+\left[\mu C_{\mathrm{p}}\right]_{\theta_{1} p_{\mathrm{m}}} \Delta p
$$

The terms on the right of equation (5) may be evaluated by experimental observation, thus giving a value for the heat added in an ideal constant pressure process. But in order to evaluate $C_{\mathbf{p}}$ at definite temperatures and pressures it is necessary to take into account the manner in which $C_{\mathrm{p}}$ changes with temperature, especially near the saturation limit. Assuming that $\left[C_{\mathrm{p}}\right]_{\mathrm{p}_{2}}$ is a function of temperature we may apply Taylor's theorem and expand in powers of $\left(\theta-\theta_{\mathrm{m}}\right)$ thus

$$
\left[C_{\mathbf{p}}\right]_{p_{2}}=\left[C_{\mathrm{p}}\right]_{p_{2} \theta_{\mathrm{m}}}+\left(\frac{\partial C_{\mathrm{p}}}{\partial \theta}\right)_{p_{2} \theta_{\mathrm{u}}}\left(\theta-\theta_{\mathrm{m}}\right)+\left(\frac{\partial^{2} C_{\mathrm{p}}}{\partial \theta^{2}}\right)_{p_{\theta_{\theta}}}\left(\theta-\theta_{\mathrm{m}}\right)^{2}+\text { etc. }
$$

Integrating both sides of this equation between the limits $\theta_{1}$ and $\theta_{2}$, we have

$$
\int_{\theta_{1}}^{\theta_{2}}\left[C_{\mathrm{p}}\right]_{p_{2}} d \theta=\left[C_{\mathrm{p}}\right]_{p_{\theta_{\mathrm{m}}}} \Delta \theta+\left(\frac{\partial^{2} C_{\mathrm{p}}}{\partial \theta^{2}}\right)_{p_{9_{\mathrm{m}}}} \frac{\Delta \theta^{3}}{24}+\left(\frac{\partial^{4} C_{\mathrm{p}}}{\partial \theta^{4}}\right)_{p_{3} \theta_{\mathrm{m}}} \frac{\Delta \theta^{5}}{1924}+\text { etc. }
$$


Combining equations (5) and (7) we have finally

$$
\left[C_{\mathrm{B}}\right]_{p_{2} \vartheta_{\mathrm{m}}}=\frac{\Delta q}{\Delta \theta}+\left[\mu C_{\mathrm{g}}\right]_{\theta_{1} p_{\mathrm{m}}} \frac{\Delta p}{\Delta \theta}-\left(\frac{\partial^{2} C_{\mathrm{p}}}{\partial \theta^{2}}\right)_{p_{2} \theta_{\mathrm{m}}} \frac{\Delta \theta^{2}}{24}-\left(\frac{\partial^{4} C_{\mathrm{p}}}{\partial \theta^{4}}\right)_{p_{2} \theta_{\mathrm{m}}} \frac{\Delta \theta^{4}}{1924}-\text { etc. }
$$

We now have the desired result, namely, a means for computing the value of $C_{\mathrm{p}}$ at a definite temperature and pressure from the observed quantities and can discuss the physical meaning of the terms. The term $\frac{\Delta q}{\Delta \theta}$ represents the quantity of heat added per degree per gram of vapor. It would equal the specific heat at the mean temperature if the experiment were performed under the ideal condition of constant pressure and in case $C_{\mathrm{p}}$ were constant or a linear function of temperature. The remaining terms in the right member of the equation represent corrections for the departure of the actual experiment from the ideal conditions. The term involving $\mu C_{\mathbf{p}}$ represents a correction for the pressure drop. For the evaluation of this correction, the Joule-Thomson coefficient $\mu$, must be known with moderate accuracy. The coefficient may be obtained with the same apparatus by means of auxiliary experiments in which the heat added electrically is zero. The remaining terms represent a correction for the variation in $C_{\mathrm{p}}$ with temperature within the temperature interval of the experiment. The magnitude of these terms can be determined only after the approximate values of $C_{\mathrm{p}}$ have been found.

The heat supplied to the vapor per unit time after the system has reached a steady state consists of two parts, namely, the heat developed by the heating coil, $E I$, and the correction for thermal leakage, $X$. Denoting by $F$ the mass of vapor flowing per unit time, the heat added to each gram of vapor is

$$
\Delta q=\frac{E I+X}{\vec{F}}
$$

A detailed account of the manner of evaluating the correction for thermal leakage is given in a later section of the paper.

\section{DETERMINATION OF JOULE-THOMSON COEFFICIENT}

As pointed out in the foregoing section, the Joule-Thomson coefficient, $\mu$, can be determined with sufficient accuracy for the evaluation of the correction for pressure drop by performing supplementary experiments in which no heat is supplied electrically. A convenient expression for evaluating $\mu$ from the quantities observed in such experiments may be obtained by introducing certain approximations in equation (8). Neglecting second and higher powers of $\Delta \theta$, assuming $\left[C_{\mathrm{p}}\right]_{p_{2} g_{\mathrm{m}}}=\left[C_{\mathrm{p}}\right]_{p_{\mathrm{m}} \theta_{1}}=\left[C_{\mathrm{p}}\right]_{p_{\mathrm{m}} \theta_{\mathrm{m}}}$, and solving for $\mu$, equation (8) gives

$$
\mu=\frac{\Delta \theta}{\Delta p}-\frac{\Delta q}{\left[C_{\mathrm{p}}\right]_{p_{\mathrm{m}} \theta_{\mathrm{m}}} \Delta p}
$$


These simplifications are very close approximations, since in any Joule-Thomson experiment performed in this calorimeter both $\Delta \theta$ and $\Delta p$ are small. Since no heat is supplied electrically in these experiments, $E I=O$.and, from equation (9) $\Delta q=\frac{X}{F}$. The above equation then reduces to

$$
\mu=\frac{\Delta \theta}{\Delta p}-\frac{X}{\left[C_{\mathrm{p}}\right]_{p_{\mathrm{m}} \theta_{\mathrm{m}}} F \Delta p}
$$

in which the last term represents a correction for heat leakage.

\section{MATERIAL}

The ammonia used in these experiments was prepared by C. S. Taylor of the chemical division of this bureau. The method of preparation has already been described in detail elsewhere ${ }^{12}$ and only a brief description of the process of purification is given here.

Commercial anhydrous ammonia, manufactured by the synthetic method, was used as a source of material. A previous analysis of this commercial ammonia indicated that it was very free from impurities with the exception of a small quantity of water. A sample was transferred by distillation from the original container into a small steel container. The first portion was discarded by blowing off the gas phase and about nine-tenths of the remainder was distilled into a similar vessel containing metallic sodium in the form of a fine wire to remove any remaining traces of water. Following this dehydration, about eight consecutive fractional distillations were made, rejecting the first and last tenths in each distillation. The first fractions were removed by blowing off the gas phase during active boiling of the liquid in order to extract the noncondensing gases present. The rejected last fractions, which remained in the container, mainly in the liquid phase, retained most of the soluble impurities.

Tests made upon several samples which were purified by the above process indicated the presence of less than 0.01 per cent by weight of water and less than 0.01 per cent by volume of noncondensing gases in the vapor phase.

A sample of about $500 \mathrm{~g}$ was used during the course of the specific heat experiments. As a matter of convenience this sample was distributed among several steel reservoirs which were used alternately as boilers and condensers, thus utilizing the ammonia repeatedly. On two occasions during the interval of time covered by the experiments the vapor pressure of the ammonia was observed in order to test the possibility of its contamination with gaseous impurities either by decomposition of the ammonia or by air leakage through

12 Composition, Purification and Certain Constants of Ammonïa. B. S. Sci. Papers, 18, p. 655; 1923 (Sci. Paper No. 465); also Refrigerating Engineering, 9, p. 213; 1923. 
the packings of the valves into the condenser line, which was usually below atmospheric pressure. In both cases the observed pressure was in agreement with the pressure corresponding to the bath temperature as calculated from the results of an independent investigation on the vapor pressure of ammonia ${ }^{13}$ within $0.3 \mathrm{~mm}$ of mercury which was within the limit of precision of the pressure observation.

\section{EXPERIMENTAL DETAILS}

\section{CALIBRATION OF APPARATUS}

Thermometers. - The two platinum resistance thermometers, designated as thermometers 1 and 2, which were used in measuring the initial and final temperatures of the ammonia vapor, were especially designed and constructed for use in the flow calorimeter. These thermometers were placed directly in the vapor stream in order to obtain the best possible indication of the temperature of the vapor. This, of course, required that they be permanently installed in the calorimeter and that means be devised for their calibration in place. They were calibrated after the calorimeter was assembled by comparison with a third standard resistance thermometer. This reference standard thermometer was immersed, throughout the comparisons and experiments, in the stirred liquid bath used to control the temperature of the calorimeter. This thermometer was used not only to calibrate thermometers 1 and 2, but also to observe the temperature of the calorimeter bath in actual experiments for the purpose of checking the nicety of the temperature regulation.

In order to bring thermometers 1 and 2 to the temperature of the reference standard for the purpose of intercomparisons, a stream of hydrogen gas at about atmospheric pressure was passed through the calorimeter. Hydrogen was used as a medium for promoting thermal equilibrium on account of its high thermal conductivity and low Joule-Thomson effect. During the comparisons, hydrogen was also admitted into the envelope space, ordinarily evacuated, to favor still further the attainment of thermal equilibrium throughout the system. For the rates of flow used, the drop in pressure of the hydrogen was not enough to cause any appreciable rise in temperature due to the Joule-Thomson effect.

Comparisons were made previous to and during the course of the experiments as follows:

\begin{tabular}{|c|c|}
\hline Date & Temperatures of comparisons \\
\hline May, $1921 \ldots$. & $40^{\circ}, 0^{\circ}, 50^{\circ}$ \\
\hline ebruary $21,1922_{2}$ & $25^{\circ}, 50^{\circ}$ \\
\hline February 23,1922 & $50^{\circ}, 75^{\circ}, 100^{\circ}, 125^{\circ}$ \\
\hline $\operatorname{arch} 8,1922 \ldots$ & $50^{\circ}, 75^{\circ}, 100^{\circ}, 125^{\circ}, 150^{\circ}$ \\
\hline $\operatorname{arch} 13,1922$ & $-40^{\circ},-20^{\circ}, 0^{\circ}$ \\
\hline $\operatorname{arch} 14,1922$ & $-40^{\circ}, 0^{\circ}$ \\
\hline $\operatorname{rch} 15,1922 \ldots$ & $-40^{\circ}$ \\
\hline
\end{tabular}

19 B. S. Sci. Papers, 16, p. 1; 1920 (Sci. Paper No. 369); also Jour. Amer. Chem. Soc., 42, p. 206; 1920; and Jour. Amer. Soc. Refrg. Eng., 6, p. 307; 1920. 
The platinum resistance thermometer, used as a reference standard in these comparisons and designated as $P t_{7}$, had been in use as a working standard in the thermometer laboratory of this bureau for several years. Its history during this time indicated constancy and reliability. The complete calibration as a primary standard at 0,100 , and $444.6^{\circ}$ (sulphur boiling point) had been recently verified. In addition, ice point observations were frequently made during the progress of the experiments as a check on its constancy.

The constants in the Callendar equation for $P t_{7}$ and the constants for 1 and 2 determined from the above comparisons are:

\begin{tabular}{|c|c|c|c|}
\hline Thermometer & $R_{0}$ & $R_{100}-R_{0}$ & $\delta$ \\
\hline $\begin{array}{l}\text { Pt } \\
1 \\
2\end{array}$ & $\begin{array}{l}25.6093 \\
27.7266 \\
27.5069\end{array}$ & $\begin{array}{r}9.9870 \\
10.8122 \\
10.7243\end{array}$ & $\begin{array}{l}1.490 \\
1.485 \\
1.470\end{array}$ \\
\hline
\end{tabular}

The calibration indicated that the readings of thermometers 1 and 2 were reliable to about $0.003^{\circ} \mathrm{C}$., with a maximum error of possibly $0.005^{\circ} \mathrm{C}$. at the higher temperatures. The sensitivity of the temperature measuring apparatus was such that readings were always possible to $0.001^{\circ} \mathrm{C}$.

Pressure Gadges. - Observations of pressure were made for two purposes. The absolute value of the pressure was one of the specifications of the state of the ammonia vapor subject to the calorimetric measurement. For this purpose high accuracy in the pressure measurement was not necessary, since the specific heat does not change rapidly with changing pressure. The other purpose of the pressure observation was to evaluate the correction term for the drop in pressure which the vapor experienced in passing through the calorimeter, and for this purpose high sensitivity could be utilized.

The three-atmosphere gauge permitted direct observations of the pressure by reading the height of the mercury column upon a steel tape graduated in millimeters. The piston gauge, which was used for measuring pressures above three atmospheres, had been calibrated previously for use in another investigation by direct comparison with an open-end mercury manometer. In actual use the pressure of the ammonia vapor was transmitted to the piston gauge, first through a short mercury manometer and thence through oil to the piston. This small manometer served to indicate when the piston was in equilibrium and with a given load on the piston served to measure small pressure differences. The reading of each of these gauges could be estimated to a fraction of a millimeter of mercury.

AUxillary Apparatus.-The auxiliary measuring apparatus consisting of the Wheatstone bridge used for the resistance thermometer observations, the two potentiometers and the electrical standards used with them, and the standard weights used in the measurements of rates of flow, had all been recently calibrated at this bureau. 


\section{EXPERIMENTAL PROCEDURE IN DETERMINATIONS OF $C_{D}$}

Preparatory to a series of determinations, one or more reservoirs, each closed by a valve and each containing about $200 \mathrm{~g}$ of the purified ammonia, were placed in the boiler bath and connected to the vapor supply line leading to the calorimeter. Two or more similar reservoirs, each containing only a small amount of ammonia, were weighed, placed in the condenser bath, and connected to the discharge line from the calorimeter. The entire line from the boilers to the, condensers was then evacuated, filled with ammonia vapor at about atmospheric pressure, and reevacuated to remove impurities.

At the beginning of an experiment the envelope of the calorimeter was evacuated to a pressure of $0.001 \mathrm{~mm}$ of mercury or less and the eracuation was continued throughout the course of an experiment. Frequent observations of this pressure were made to help control and evaluate the thermal leakage. Even at $150^{\circ}$ C. no great difficulty was experienced in maintaining a pressure within the envelope of $0.001 \mathrm{~mm}$ of mercury after this pressure had been once attained; but it may be remarked that this was accomplished at the expense of considerable toil and patience in the discovery and repair of leaks.

Each of the three baths was brought to the desired temperature, which was thenceforth controlled. Close adjustment of the temperatures of the boiler and condenser baths was not required. After a little experience it was not difficult to choose a temperature of the boiler bath which was favorable to good regulation of the rate of flow. In the experiments at pressures less than about five atmospheres the temperature of this bath was usually maintained constant. In experiments at higher pressures, and also in those with the larger flows, better flow regulation was found possible when the bath temperature was made to rise slowly. The only requirement of the condenser bath temperature was that it be kept low enough to prevent the back pressure of the vapor from affecting the rate of discharge through the orifices. Experiments showed that this condition was realized when the indicated pressure on the condenser line was less than 35 per cent of the fore pressure on the orifices.

In most of the experiments a condenser bath temperature of $-45^{\circ} \mathrm{C}$. was found sufficiently low. In a few experiments at about one-half atmosphere pressure, and some with high rates of flow, lower condenser temperatures were maintained with the use of liquid air. The calorimeter bath temperature required extremely close regulation. This temperature was maintained constant to about $0.001^{\circ} \mathrm{C}$. by means of the thermoregulator.

When all was ready, the flow was started. The final pressure, $p_{2}$, in the calorimeter was adjusted to the desired value and thereafter maintained constant by means of the pressure regulator. The calorimeter heating current from a storage battery was then turned on and 
adjusted to produce the desired rise in temperature of the vapor. Heating current was also supplied to the guard heater in order to maintain the surface of the guard at the same temperature as the surface of the calorimeter system which it surrounds, and thus help control thermal leakage.

After the rate of flow and the calorimeter heating current had been maintained constant for a period of about one-half hour, observations were made periodically of the initial and final temperatures of the vapor. The constancy of these observations served to indicate that the calorimeter had reached a steady state. The initial and final pressures were then observed alternately, using the same pressure gauge, and a determination of the rate of flow was started by diverting the flow into a weighed reservoir.

During the flow determination several potentiometer readings were made of the current and potential drop in the calorimeter heating coil; the initial and final temperatures of the vapor were observed frequently, and the current in the guard heater was manually controlled to maintain a constant indication of the regulating thermocouples. After a chosen interval of time, usually 20 minutes, the flow was again diverted to another reservoir. This procedure provided the data for a single determination of specific heat, and could be repeated as often as desired.

The flow determinations were started and stopped on minute signals as indicated by a telegraph sounder which was operated by the standard clock of the bureau. The following procedure was adopted in order to avoid error in evaluating the duration of the flow determination. The minute signal from the clock gave the time for starting to close the valve to the condensing reservoir. When this was closed the valve to a weighed reservoir was opened. During the fraction of a second when both valves were closed the pressure in the condenser line did not rise to a value which would affect the rate of flow through the orifices and calorimeter. The same procedure was followed at the end of the time interval, first closing the valve to the weighed reservoir and then opening the valve to another reservoir.

Special handles were attached to these valve stems to facilitate rapid operation. With practice the time required to open or close a valve was less than one second and slight variations in the procedure at the beginning and end of the flow determinations introduced an error of only a small fraction of a second in the time interval, which was usually 1,200 seconds.

The weighed reservoirs, after a charge, were removed from the condenser bath, washed with water under the tap to bring them to room temperature, wiped with a towel, and placed for several minutes in a blast from an electric fan to bring them to room temperature and reference surface conditions before weighing. 
All mass determinations were made to $1 \mathrm{mg}$ by comparing the differences of the mass of the weighed reservoir with that of a dummy, substituted just before or just after the weighing. The dummy was one of the set of reservoirs and in form and surface was essentially identical with the rest of the set. The differences in weight were measured with platinum-plated brass weights placed on the same arm of the balance with the weighed reservoirs.

In carrying out the experiments it was found desirable and convenient to utilize the services of four persons in making the numerous manipulations, adjustments, and readings. The duties of this staff were apportioned somewhat as follows: First, regulation of boiler bath and rate of flow, manipulation and adjustment of pressureregulating mechanism, orifices and appropriate valves, observations of the initial and final pressures in the calorimeter; second, operation of vacuum pumps and condenser bath, observations of jacket pressure, weighings and manipulations in the determinations of the rate of flow; third, regulation of calorimeter bath, and electric heating, adjustment of current in guard heater, observations of the power, thermometers and thermocouples; fourth, recording of all observations and computation of results.

\section{EXPERIMENTAL PROCEDURE IN DETERMINATIONS OF $\mu$}

The procedure in the determinations of the Joule-Thomson coefficient, $\mu$, was similar to that followed in the specific heat experiments, except that no electric heating was employed and the rate of flow was not measured during the course of those determinations. Frequently when working with the larger rates of flow such an experiment was made at the beginning of the day's observations because the calorimeter could be brought into approximate temperature equilibrium with comparative ease at that time. These experiments were not made previous to each specific heat experiment because of the length of time required to bring the calorimeter into temperature equilibrium after a portion of it had been heated several degrees in a preceding experiment and also because the correction for the effect of pressure drop in any experiment could be determined better from the data obtained with large flows.

\section{THERMAL LEAKAGE}

It has already been pointed out in Section II that the conservation of the measured heat intentionally added to the vapor and the avoidance of unmeasured heat leakage to or from the vapor are vital to the accuracy of the experimental results since the specific heat can be determined no more accurately than can the net amount of heat which the vapor gains in passing from the initial to the final state. The means adopted to meet these ideal conditions are: (1) Construction and operation of the calorimeter so as to make the 
thermal leakage small, and (2) determination of the small amount of thermal leakage as a correction to the directly measured heat added. The constructive means have already been described and in operation they were found effective to the extent that only rarely did the correction for thermal leakage exceed 0.2 per cent of the entire heat supplied in any experiment. We shall next proceed to describe how this correction was evaluated.

The configuration of the apparatus is too complex to permit an analysis of the thermal leakage by the numerous possible paths and the alternative course was followed of evaluating the entire correction empirically. The fact that only a small quantity of heat remains to be evaluated after the means for reducing the thermal leakage had been effected, makes the selection of an empirical relation less critical than would otherwise be the case. What is more vital here is the method of testing as to the correctness of the evaluation of the leakage. This method is discussed later.

The empirical relation adopted to correct all the experiments for thermal leakage is

$$
X=(N-0.2 \Delta \theta) x
$$

in which $N$ is the number of microvolts indicated by the regulating thermocouples on the guard and heater shield, $\Delta \theta$ is the observed temperature rise of the vapor expressed in degrees centigrade and $x$ is the coefficient of thermal leakage; that is, the ratio between the total thermal leakage $X$ and the mean effective temperature difference between the calorimeter system and its immediate surroundings. Experiments showed that this mean effective temperature difference could be obtained by applying a correction of $0.2 \Delta \theta$ to the indicated temperature difference between the guard and the heater shield. The fact that the regulating thermocouples did not always indicate this exact mean effective temperature difference may have been the result either of imperfections of the individual couples or of the inherent difficulty of determining the average temperature of a complicated surface by means of a limited number of couples.

$N$ and $\Delta \theta$ were observed in each determination of the specific heat, but the coefficient, $x$, required supplementary experiments to determine its value for various temperatures of the calorimeter and various degrees of evacuation of the envelope space. The coefficient of thermal leakage, $x$, was determined for any single combination of experimental conditions by making two successive, but separate experiments, in which the only conditions varied sensibly were the indicated temperature difference between the calorimeter shield and guard, $N$, and the resulting change in the temperature rise of the vapor, $\Delta \theta$.

These two coordinate changes were observed, the first by means of the regulating thermocouples on the shield and guard, and the second by means of the resistance thermometers in the vapor stream, 
precisely as in a determination of the specific heat. In order to express numerically the results obtained by this procedure, equations (9) and (12) may be substituted in equation (8) and the result written as

$$
\left[C_{\mathrm{p}}\right]_{p_{2} \theta_{\mathrm{m}}}=\frac{E I+(N-0.2 \Delta \theta) x}{F \Delta \theta}+\left[\mu C_{\mathrm{p}}\right]_{p_{\mathrm{m}} \theta_{1}} \frac{\Delta p}{\Delta \theta}-\left(\frac{\delta^{2} C_{\mathrm{p}}}{\delta \theta^{2}}\right)_{p_{2} \theta_{\mathrm{m}}} \frac{\Delta \theta^{2}}{24}-\text { etc. }
$$

The two experiments yield two equations of this form in which the values of $C_{\mathrm{p}}$ at the respective mean temperatures are practically identical. Since determinations of $x$ to a very moderate degree of accuracy are sufficient to evaluate the small amount of thermal leakage we may neglect the small differences of the correction terms and write

$$
\frac{E I+\left(N_{\mathrm{a}}-0.2 \Delta \theta_{\mathrm{a}}\right) x}{\Delta \theta_{\mathrm{a}}}=\frac{E I+\left(N_{\mathrm{b}}-0.2 \Delta \theta_{\mathrm{b}}\right) x}{\Delta \theta_{\mathrm{b}}}
$$

in which the subscripts refer to experiments $a$ and $b$. Solving this equation for $x$, we obtain

$$
x=\frac{E I\left(\Delta \theta_{\mathrm{b}}-\Delta \theta_{\mathrm{a}}\right)}{N_{\mathrm{a}} \Delta \theta_{\mathrm{b}}-N_{\mathrm{b}} \Delta \theta_{\mathrm{a}}}
$$

The units in which the leakage coefficient; $x$, is expressed are watts per microvolt. It may be recalled that $x$ is by definition the thermal leakage per unit temperature difference between the calorimeter system and its surroundings. Since the leakage takes place chiefly by radiation, and metallic and gaseous conduction, we may expect $x$, in general, to vary with the temperature of the calori-

\begin{tabular}{|c|c|c|c|c|c|c|c|c|c|}
\hline \multirow[b]{2}{*}{ Date } & \multirow[b]{2}{*}{$E I$} & \multirow[b]{2}{*}{$\Delta \theta_{\mathbf{a}}$} & \multirow[b]{2}{*}{$\Delta \theta_{\mathrm{b}}$} & \multirow[b]{2}{*}{$\Delta \theta_{\mathrm{a}}-\Delta \theta_{\mathrm{b}}$} & \multirow[b]{2}{*}{$N_{\mathrm{a}}$} & \multirow[b]{2}{*}{$N_{\mathrm{b}}$} & \multicolumn{2}{|c|}{ Envelope } & \multirow[b]{2}{*}{$x$} \\
\hline & & & & & & & Pressure & $\begin{array}{c}\text { Temper- } \\
\text { ature }\end{array}$ & \\
\hline $\begin{array}{l}\text { Nov. } 8,1921 \\
\text { Do } \\
\text { Nov. } 11,1921 \\
\text { Nov. } 22,1921 \\
\text { Nov. } 26,1921\end{array}$ & $\begin{array}{l}\text { Watts } \\
0.3160 \\
.3160 \\
.1864 \\
.1087 \\
.1109\end{array}$ & $\begin{array}{r}{ }^{\circ} \mathrm{C} \\
10.998 \\
11.073 \\
9.383 \\
10.733 \\
8.899\end{array}$ & $\begin{aligned}{ }^{\circ} C \\
11.073 \\
10.800 \\
9.183 \\
11.040 \\
9.085\end{aligned}$ & $\begin{array}{l}{ }^{\circ} \mathrm{C} \\
-0.075 \\
+.273 \\
+.200 \\
-.307 \\
-.186\end{array}$ & $\begin{array}{l}\mu v \\
+0.7 \\
+7.0 \\
+0.1 \\
0.0 \\
+0.1\end{array}$ & $\begin{array}{l}\mu v \\
+7.0 \\
-16.0 \\
-12.1 \\
+10.0 \\
+10.0\end{array}$ & $\begin{array}{l}m m \quad H g \\
\end{array}$ & $\begin{array}{r}{ }^{\circ} \mathrm{C} \\
41 \\
41 \\
40 \\
21 \\
-11\end{array}$ & $\begin{array}{r}\text { Watts/ } / 0 \\
0.00034 \\
.00034 \\
.00033 \\
.00031 \\
.00023\end{array}$ \\
\hline $\begin{array}{l}\text { Nov. } 28,1921 \\
\text { Feb. }{ }^{1}, 1922 \\
\text { Do } \\
\text { Do } \\
\text { Feb. } 2,1922\end{array}$ & $\begin{array}{l}.0592 \\
.2153 \\
.2151 \\
.2156 \\
.2135\end{array}$ & $\begin{array}{l}5.804 \\
9.310 \\
9.344 \\
9.347 \\
9.249\end{array}$ & $\begin{array}{l}6.161 \\
8.652 \\
8.952 \\
9.221 \\
9.038\end{array}$ & $\begin{array}{l}-.357 \\
+.658 \\
+.392 \\
+.126 \\
+.211\end{array}$ & $\begin{array}{r}0.0 \\
0.0 \\
0.0 \\
+0.1 \\
0.0\end{array}$ & $\begin{array}{r}+10.0 \\
-9.9 \\
-10.2 \\
-10.0 \\
-10.0\end{array}$ & $\begin{array}{l}10.3 \\
.12 \\
.0007 \\
.0110\end{array}$ & $\begin{array}{l}59 \\
39 \\
39 \\
40 \\
39\end{array}$ & $\begin{array}{l}.00036 \\
.00154 \\
.00088 \\
.00029 \\
.00049\end{array}$ \\
\hline $\begin{array}{l}\text { Do } \\
\text { Do } \\
\text { Feb. } \quad 3,1922 \\
\text { Feb. } \quad 7,1922\end{array}$ & $\begin{array}{l}.2131 \\
.2128 \\
.2294 \\
.3878\end{array}$ & $\begin{array}{l}9.236 \\
9.221 \\
9.875 \\
9.654\end{array}$ & $\begin{array}{l}9.045 \\
9.104 \\
9.768 \\
9.591\end{array}$ & $\begin{array}{l}+.191 \\
+.117 \\
+.107 \\
+.063\end{array}$ & $\begin{array}{r}0.0 \\
0.0 \\
+3.0 \\
+3.0\end{array}$ & $\begin{array}{r}-10.0 \\
-10.0 \\
-7.0 \\
-7.0\end{array}$ & $\begin{array}{l}.0080 \\
.0005 \\
.0001 \\
.0001\end{array}$ & $\begin{array}{l}39 \\
39 \\
40 \\
40\end{array}$ & $\begin{array}{l}.00044 \\
.00027 \\
.00025 \\
.00026\end{array}$ \\
\hline $\begin{array}{lr}\text { Feb. } & 9,1922 \\
\text { Feb. } & 15,1922 \\
\text { Feb. } & 28,1922 \\
\text { Mar. } & 3,1922\end{array}$ & $\begin{array}{l}.3526 \\
.2331 \\
.1824 \\
.3298\end{array}$ & $\begin{array}{r}9.800 \\
10.258 \\
9.968 \\
9.937\end{array}$ & $\begin{array}{r}9.725 \\
10.125 \\
9.632 \\
9.811\end{array}$ & $\begin{array}{l}+.075 \\
+.133 \\
+.336 \\
+.126\end{array}$ & $\begin{array}{l}+3.0 \\
+3.0 \\
+3.0 \\
+1.5\end{array}$ & $\begin{array}{l}-6.9 \\
-7.1 \\
-7.0 \\
-8.5\end{array}$ & $\begin{array}{l}.0003 \\
.0004 \\
.0090 \\
.0005\end{array}$ & $\begin{array}{r}60 \\
80 \\
155 \\
155\end{array}$ & $\begin{array}{r}.00027 \\
.00030 \\
.00062 \\
.00042\end{array}$ \\
\hline $\begin{array}{l}\text { Mar. } 9,1922 \\
\text { Mar. } 11,1922 \\
\text { Mar. } 17,1922 \\
\text { Mar. } 21,1922\end{array}$ & $\begin{array}{l}.3365 \\
.6118 \\
.2504 \\
.1348\end{array}$ & $\begin{array}{r}9.754 \\
48.784 \\
10.017 \\
5.936\end{array}$ & $\begin{array}{r}9.660 \\
48,482 \\
9.950 \\
5.892\end{array}$ & $\begin{array}{l}+.094 \\
+.302 \\
+.067 \\
+.044\end{array}$ & $\begin{array}{r}+3.0 \\
+8.0 \\
+3.0 \\
0.0\end{array}$ & $\begin{array}{l}-7.0 \\
-2.0 \\
-7.0 \\
-7.0\end{array}$ & $\begin{array}{l}.0002 \\
.0001 \\
.0001 \\
.0001\end{array}$ & $\begin{array}{r}120 \\
137 \\
5 \\
-12\end{array}$ & $\begin{array}{r}.00033 \\
.00038 \\
.00017 \\
.00014\end{array}$ \\
\hline
\end{tabular}
meter and the pressure of the gas within the envelope.

TABLE 1.-Determinations of thermal leakage coefficient $x$ 
The results of several determinations of $x$ at various calorimeter temperatures and envelope pressures are given in Table 1 . The results are also shown in Figures 5 and 6 . These results indicate, as shown in Figure 5, that at constant temperature $x$ is a linear function of the envelope pressure for pressures below $0.01 \mathrm{~mm}$ mercury. The increase in the leakage with the envelope pressure may be interpreted as an increase in the gaseous conduction, since the leakage by other means is but slightly affected by the gas pressure. The linear relation shown in Figure 5 is in accord with kinetic theory, which states that gaseous conduction is directly proportional to the pressure of the gas at low pressures where the mean free path of the molecules is large compared with the distance between the boundaries of the conducting space. Thus, at zero pressure the gaseous conduction may be considered zero and the intercepts of the lines in Figure 5 with the axis of zero pressure are indications of the leakage by radiation and metallic conduction. It may be noted that the leakage by

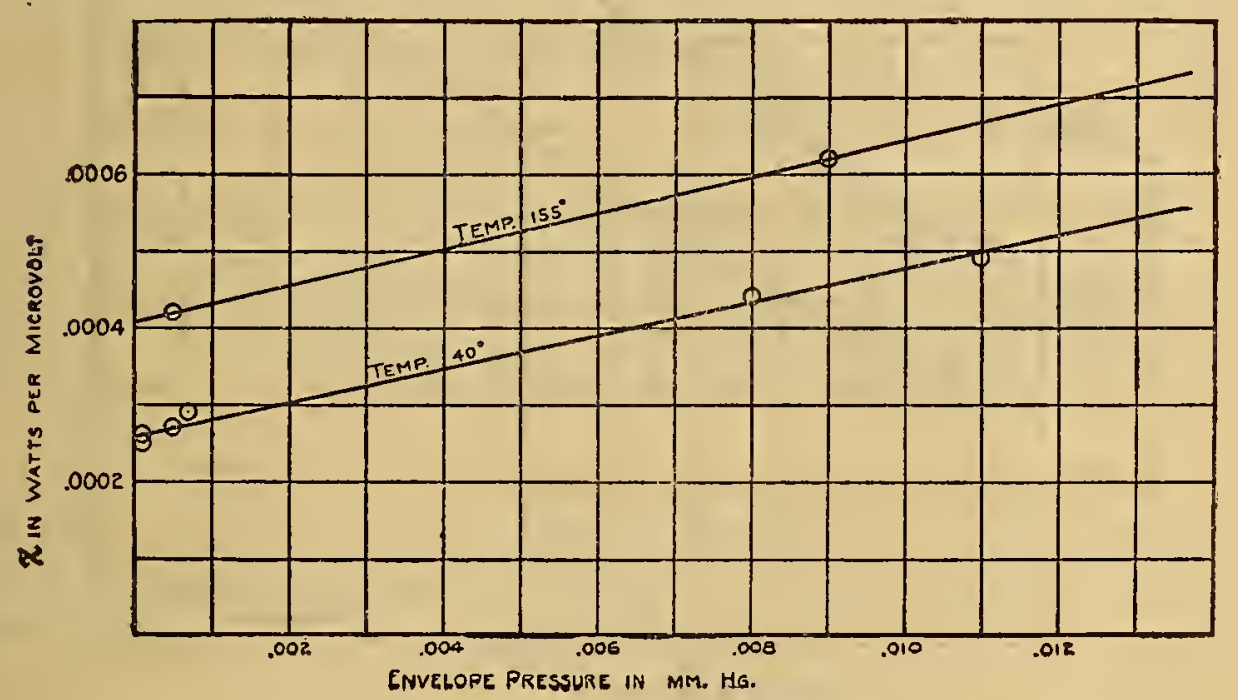

Fig. 5.-Variation of thermal leakage coefficient, $x$, with evacuation

these paths is large compared with the leakage by gaseous conduction in those experiments in which the envelope pressures are below 0.001 mim of mercury.

The determinations of $x$, which were made in 1922 with the envelope pressure below $0.001 \mathrm{~mm}$ of mercury, are shown in Figure 6 , and indicate that $x$ is approximately a linear function of the calorimeter temperature. The determinations made in 1921, without observing the envelope pressure throughout the experiments, are also shown in Figure 6 and indicate that the gaseous conduction was greater in these experiments. It is estimated by means of Figure 5 and by readings taken with the McLeod gauge previous to these experiments that the envelopes pressures were probably less than $0.005 \mathrm{~mm}$ of mercury. A discussion of the 1921 experiments and the reasons for not observing the envelope pressure are given in the next section. 
Consideration has been given thus far to the evaluation of the correction for thermal leakage. We shall now consider the method of testing the correctness of this evaluation. The method chosen is based upon the assumption that the thermal leakage is independent of the power input and rate of flow as long as the temperature rise is sensibly constant. In other words, it is assumed that the temperature distribution within the calorimeter is independent of the power input and rate of flow under these conditions. There is experimental evidence in support of this assumption, for the indications of the thermocouples were found to be but slightly changed by doubling the rate of flow and keeping the temperature rise constant.

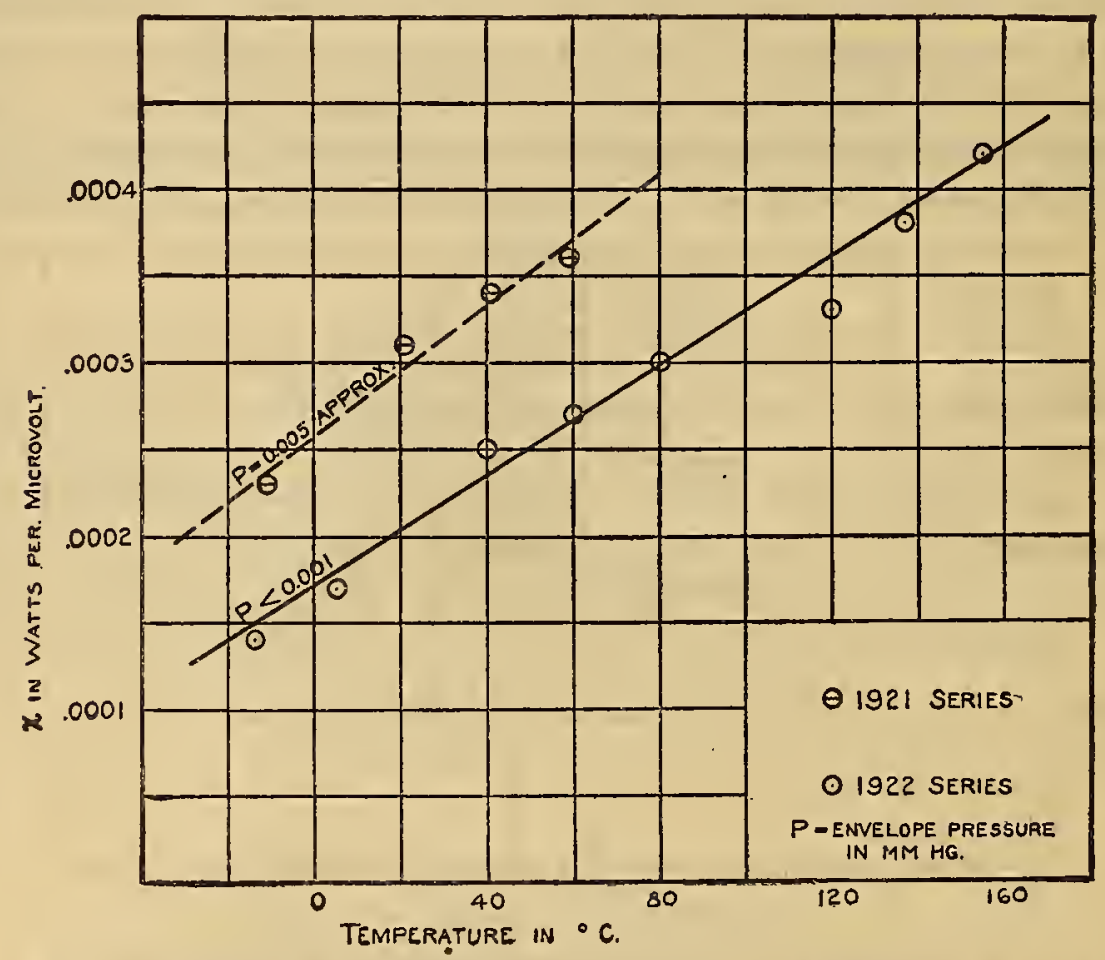

FIG. 6.-Variation of thermal leakage coefficient, $x$, with temperature

The principle of the method was to perform two or more specific heat experiments at the same temperature and pressure with approximately the same temperature rise, but different power inputs and different rates of flow.

The test of the proper correction for thermal leakage is that the values of $C_{\mathrm{p}}$ obtained from these experiments shall be independent of the rate of flow. Any appreciable outstanding leakage, which is not accounted for, will produce a different percentage error in the values computed for the heat added and consequently the resulting values of $C_{\mathrm{p}}$ will vary with the rate of flow. With very large flows the leakage will become negligible in comparison with the power input. Thus, by plotting the values of $C_{\mathrm{p}}^{y}$ against the reciprocal of 
the rate of flow and extrapolating to infinite flow, the correct value of $C_{\mathrm{p}}$ may be obtained. This method of procedure is often called the method of extrapolation to infinite flow. This method was used in the selection of the empirical relation of equation (12), but the ultimate test of the validity of the correction for thermal leakage was the constancy of the final result, $C_{\mathbf{p}}$, with various rates of flow.

Experiments were performed with various rates of flow at each of the seven temperatures chosen for experimentation. That the above test was satisfied within the limits of accidental error is shown by the results given in Tables 3 and 4 . It may be remarked incidentally that the constancy of the values of $C_{\mathrm{p}}$ obtained from experiments with different rates of flow is a crucial test not only of the correction for thermal leakage, but also of the Joule-Thomson correction for pressure drop.

TABLE 2.-Determinations of $C_{p}$ at $35^{\circ} \mathrm{C}$. and $1.5 \mathrm{~m}$ of mercury

\begin{tabular}{|c|c|c|c|c|c|c|c|c|c|c|}
\hline \multirow{2}{*}{ Date } & \multirow{2}{*}{$\begin{array}{l}\text { Regu- } \\
\text { lating } \\
\text { couples } \\
N\end{array}$} & \multirow{2}{*}{$\begin{array}{c}\text { Power } \\
\text { EI }\end{array}$} & \multirow{2}{*}{$\underset{F}{\text { Flow }}$} & \multirow{2}{*}{$\begin{array}{c}\text { Temp. } \\
\text { rise } \\
\Delta \theta\end{array}$} & \multirow{2}{*}{$\begin{array}{c}\text { Pressure } \\
\text { drop } \\
\Delta p\end{array}$} & \multirow{2}{*}{$\begin{array}{l}\mathrm{J}-\mathrm{T} \text { cor- } \\
\text { rection } \\
\mu C_{\mathrm{p}} \frac{\Delta p}{\Delta \theta}\end{array}$} & \multirow{2}{*}{$\begin{array}{l}\text { Enve- } \\
\text { lope } \\
\text { pressure }\end{array}$} & \multicolumn{2}{|c|}{$C_{\mathrm{p}}$} & \multirow{2}{*}{$\begin{array}{c}\text { Recip- } \\
\text { rocal } \\
\text { of } \\
\text { flow } \\
\frac{1}{F}\end{array}$} \\
\hline & & & & & & & & Obs. & Cor. & \\
\hline $\begin{array}{l}1922 \\
\text { Jan. } 26 \\
\text { Jan. } 27 \\
\text { Feb. } 1 \\
\text { Feb. } 2 \\
\text { Feb. } 3 \\
\text { Do }\end{array}$ & $\begin{array}{r}\mu v \\
0.0 \\
.0 \\
.0 \\
.0 \\
3.0 \\
3.0\end{array}$ & $\begin{array}{c}\text { Watts } \\
0.48168 \\
.84251 \\
.21559 \\
.21280 \\
.73374 \\
.22917\end{array}$ & $\begin{array}{c}\text { g/sec. } \\
0.023159 \\
.038773 \\
.010314 \\
.010315 \\
.033218 \\
.010423\end{array}$ & $\begin{array}{l}{ }^{\circ} C . \\
9.242 \\
9.531 \\
9.350 \\
9.224 \\
9.742 \\
9.864\end{array}$ & $\begin{array}{c}m H g \\
-0.028 \\
-.067 \\
-.008 \\
-.008 \\
-.053 \\
-.008\end{array}$ & $\begin{array}{r}\underbrace{\text { Jog }}_{\text {Joules }} \\
-0.0232 \\
-.0538 \\
-.0065 \\
-.0066 \\
-.0425 \\
-.0064\end{array}$ & $\begin{array}{r}m m \mathrm{Hg} \\
0.0004 \\
.0008 \\
.0007 \\
.0005 \\
.0002 \\
.0002\end{array}$ & $\begin{array}{l}\text { Joules } \\
\text { gdeg. } \\
2.2273 \\
2.2261 \\
2.2291 \\
2.2300 \\
2.2249 \\
2.2231\end{array}$ & $\begin{array}{l}\frac{\text { Joules }}{\text { gdeg. }} \\
2.2251 \\
2.2248 \\
2.2241 \\
2.2250 \\
2.2255 \\
2.2257\end{array}$ & $\begin{array}{r}s e c . / g \\
43.18 \\
25.79 \\
96.96 \\
96.95 \\
30.10 \\
95.90\end{array}$ \\
\hline
\end{tabular}

As an example of the information furnished by experiments with different rates of flow, the results of several such experiments are given in Table 2. These experiments wero performed at a mean temperature of $35^{\circ}$ and a pressure of $1.5 \mathrm{~m}$ of mercury with approximately $10^{\circ}$ temperature rises. The apparent or observed values of $C_{\mathrm{p}}$ are plotted in Figure 7 against the reciprocal of the flow. In the first series of experiments the indication of the regulating thermocouples was made zero $(N=0)$. The results indicated that a small quantity of heat was lost from the system, amounting to about 0.2 per cent of the heat supplied electrically at the lowest rate of flow. Two experiments were then performed with a regulating thermocouple indication of $3 \mathrm{mv}(N=3)$ in order to compensate for this heat loss. As shown graphically in Figure 7 , these experiments indicated a slight overcompensation. Correcting all of the experiments to $N=2$ gave values of $C_{\mathbf{p}}$, which were constant within a few hundredths of a per cent. These experiments, together with others in which the temperature rises were approximately 5 and $50^{\circ}$, led to the selection of the empirical relation given by equation (12). 


\section{PRELIMINARY EXPERIMENTS ON $C_{p}$}

In the series of experiments on specific heat performed in 1921 the importance of systematic control and observation of the residual envelope pressure was not recognized. Attempts to evaluate the thermal leakage correction in these experiments led to the installation of an additional vacuum pump and McLeod gauge in January, 1922, in order to obtain continuous service in the control and measurement of the envelope pressure.

During the progress of the final experimental series in 1922 (see Table 3) it was conclusively demonstrated that in order to evaluate the thermal leakage correction accurately it was necessary not only

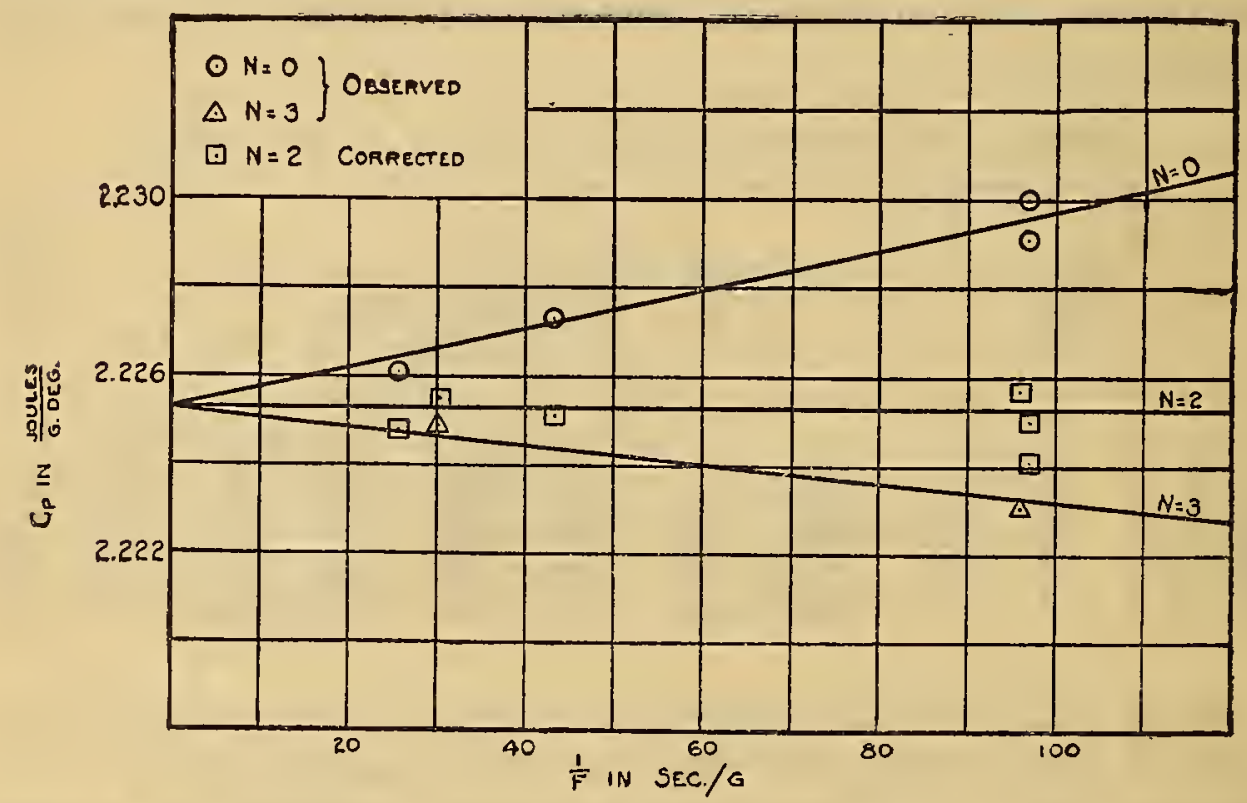

FIG. 7.-Variation of apparent specific heat with rate of flow, F., and thermocouple indication, $N$

to employ a certain degree of evacuation in the envelope space, but also to determine and control the constancy of the pressure therein.

Most of the 1921 experiments were made with small rates of flow in order to study the behavior of the various instruments more easily and also to acquire experience in manipulation. On account of the small rates of flow and the relatively high and indefinite pressure in the envelope space, the correction for thermal leakage was comparatively large and also uncertain. The results are, therefore, not as reliable as those obtained in the later series of experiments. The results are given as a matter of record in Table 5, but they have been excluded from the list of accredited determinations and no weight given to them in the final results. 


\section{EXPERIMENTS NEAR SATURATION}

On account of the rapid increase in the value of $C_{\mathrm{p}}$ in the neighborhood of the saturation limit, several experiments were made in which the aim was to approach this boundary as closely as could be done safely. The danger in these experiments, of course, is the possibility of liquefaction taking place in the calorimeter and the uncertainty as to the result of such an occurrence.

In order to investigate what would happen in close proximity to saturation, an experiment was made on November 16, 1921, in which the calorimeter bath temperature was $-5^{\circ} \quad C$., and the pressure corresponded to $2^{\circ}$ of superheat. No peculiarity in behavior was observed in any respect, and two complete determinations of $C_{\mathrm{p}}$ were obtained. After completing these determinations the pressure in the calorimeter was increased gradually, noting meanwhile the indications of the thermometers. When the pressure reached a value corresponding to $0.8^{\circ}$ superheat, thermometer $T_{1}$ began to show slight fluctuations in temperature. These fluctuations increased as the pressure was raised until they became so large as to preclude reliable observations. The trend of this fluctuating temperature was upward as the pressure was raised. Upon stopping the flow the temperature promptly dropped several degrees, just as it would if liquid ammonia were present in that thermometer cell.

On the following day it was found that the calorimeter heater had developed a short circuit to its case. A plausible explanation was that a small particle of conducting material, such as a metal chip, had lodged between the coil windings and the case. This mishap did not preclude the use of the instrument, as the resistance of the heating coil still remained constant, but it was necessary to avoid grounding any other part of the heating circuit. Later on the fault disappeared. On November 18, 1921, two additional experiments with $2^{\circ}$ of superheat were successfully made.

The foregoing experiments demonstrated that too close approach to the saturation limit caused pronounced manifestations of unsteadiness, and it was inferred that the appearance of unsteadiness marked the danger point in approach to saturation. The observations taken with $2^{\circ}$ of superheat were believed to be far enough removed from this danger point to be reliable.

On February 13, 1922, two experiments were made with about 20 atmospheres pressure and approximately $3^{\circ}$ of superheat. The temperature rise in these experiments was about $5^{\circ}$, and the agreement in the results was remarkably good. The time interval covered in these experiments was about two hours, and the measuring instruments indicated very steady conditions.

On March 28, 1922, an experiment was made with $0.9^{\circ}$ superheat. In this experiment fluctuations of about $0.01^{\circ}$ were observed in thermometer $T_{1}$. After completing the various measurements, an attempt was made to reduce the rate of flow and obtain a check 
TABLE 3.-Calorimeter data on $C_{\mathrm{D}}$

\begin{tabular}{|c|c|c|c|c|c|c|c|c|}
\hline Date & $\begin{array}{c}\text { Mean } \\
\text { tempera- } \\
\text { ature } \\
\theta_{\infty}\end{array}$ & $\begin{array}{c}\text { Temper- } \\
\text { ature } \\
\text { rise } \\
\Delta \theta\end{array}$ & $\begin{array}{c}\begin{array}{c}\text { Final } \\
\text { pressure }\end{array} \\
p_{2}\end{array}$ & $\begin{array}{l}\text { Pressure } \\
\text { drop } \\
-\Delta p\end{array}$ & $\begin{array}{c}\text { Rate of } \\
\text { flow } \\
F\end{array}$ & $\begin{array}{l}\text { Power } \\
\qquad E I\end{array}$ & $\begin{array}{c}\text { Thermal } \\
\text { leakage } \\
(\mathrm{N}-0.2 \Delta \theta) x\end{array}$ & $\begin{array}{l}\text { Num- } \\
\text { ber of } \\
\text { deter- } \\
\text { mina- } \\
\text { tions }\end{array}$ \\
\hline 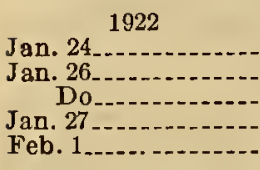 & $\begin{array}{l}{ }^{\circ} C . \\
34.99 \\
35.03 \\
34.92 \\
35.00 \\
34.97\end{array}$ & $\begin{array}{l}{ }^{\circ} C . \\
9.376 \\
9.386 \\
9.242 \\
9.532 \\
9.350\end{array}$ & $\begin{array}{l}m \mathrm{Hg} \\
1.495 \\
1.500 \\
1.501 \\
1.498 \\
1.500\end{array}$ & $\begin{array}{l}m \mathrm{Hg} \\
0.0080 \\
.0078 \\
.0280 \\
.0670 \\
.0075\end{array}$ & $\begin{array}{l}\text { g/sec. } \\
0.010242 \\
.010226 \\
.023158 \\
.038773 \\
.010314\end{array}$ & $\begin{array}{l}\text { Watts } \\
0.21462 \\
.21450 \\
.48161 \\
.84253 \\
.21559\end{array}$ & $\begin{array}{l}\text { Watts } \\
-0.00046 \\
-.00050 \\
-.00043 \\
-.00049 \\
-.00052\end{array}$ & $\begin{array}{l}1 \\
2 \\
2 \\
1 \\
2\end{array}$ \\
\hline $\begin{array}{l}\text { Feb. } 2 \\
\text { Feb. } 3 \\
\text { Do } \\
\text { Feb. } 6 \\
\text { Do }\end{array}$ & $\begin{array}{l}34.93 \\
35.08 \\
35.23 \\
35.21 \\
35.32\end{array}$ & $\begin{array}{r}9.225 \\
9.742 \\
9.869 \\
9.876 \\
10.002\end{array}$ & $\begin{array}{l}1.498 \\
1.501 \\
1.498 \\
2.308 \\
2.306\end{array}$ & $\begin{array}{l}.0080 \\
.0528 \\
.0078 \\
.0385 \\
.0100\end{array}$ & $\begin{array}{l}.010315 \\
.033218 \\
.010428 \\
.035915 \\
.016162\end{array}$ & $\begin{array}{l}.21280 \\
.73374 \\
.22929 \\
.82538 \\
.37228\end{array}$ & $\begin{array}{l}+.00050 \\
+.00026 \\
+.00026 \\
+.00026 \\
+.00026\end{array}$ & $\begin{array}{l}1 \\
1 \\
2 \\
1 \\
1\end{array}$ \\
\hline $\begin{array}{l}\text { Feb. } 7 \\
\text { Do } \\
\text { Feb. } 8 \\
\text { Do } \\
\text { Feb. } 9\end{array}$ & $\begin{array}{l}35.12 \\
35.08 \\
35.17 \\
35.11 \\
55.08\end{array}$ & $\begin{array}{r}9.654 \\
9.564 \\
9.931 \\
9.813 \\
10.009\end{array}$ & $\begin{array}{l}4.054 \\
4.053 \\
7.110 \\
7.115 \\
2.290\end{array}$ & $\begin{array}{l}.0049 \\
.0049 \\
.0035 \\
.0035 \\
.0395\end{array}$ & $\begin{array}{l}.016214 \\
.016303 \\
.015906 \\
.016082 \\
.034386\end{array}$ & $\begin{array}{r}.38780 \\
.38608 \\
.45312 \\
.45294 \\
.79000\end{array}$ & $\begin{array}{l}+.00026 \\
+.00026 \\
+.00026 \\
+.00026 \\
+.00028\end{array}$ & $\begin{array}{l}1 \\
1 \\
1 \\
1 \\
1\end{array}$ \\
\hline $\begin{array}{r}\text { Do.... } \\
\text { Do.... } \\
\text { Feb. } 10 \ldots \\
\text { Do.-. } \\
\text { Feb. } 11\end{array}$ & $\begin{array}{l}55.02 \\
55.01 \\
55.06 \\
55.10 \\
55.04\end{array}$ & $\begin{array}{l}9.800 \\
9.772 \\
9.906 \\
9.981 \\
9.729\end{array}$ & $\begin{array}{r}\text { 2. } 288 \\
2.291 \\
3.969 \\
7.063 \\
10.391\end{array}$ & $\begin{array}{l}.0105 \\
.0105 \\
.0045 \\
.0020 \\
.0022\end{array}$ & $\begin{array}{l}.015822 \\
.015851 \\
.015805 \\
.015976 \\
.015118\end{array}$ & $\begin{array}{l}.35275 \\
.35238 \\
.37338 \\
.41826 \\
.43471\end{array}$ & $\begin{array}{l}+.00028 \\
+.00028 \\
+.00028 \\
+.00028 \\
+.00028\end{array}$ & $\begin{array}{l}1 \\
1 \\
2 \\
2 \\
1\end{array}$ \\
\hline $\begin{array}{l}\text { Do } \\
\text { Feb. 13 } \\
\text { Do } \\
\text { Feb. } 14 \\
\text { Do }\end{array}$ & $\begin{array}{l}55.06 \\
54.94 \\
54.97 \\
54.93 \\
54.96\end{array}$ & $\begin{array}{l}9.763 \\
4.714 \\
4.773 \\
4.694 \\
4.707\end{array}$ & $\begin{array}{r}10.392 \\
15.106 \\
15.105 \\
1.503 \\
1.505\end{array}$ & $\begin{array}{l}.0022 \\
.0018 \\
.0018 \\
.0290 \\
.0080\end{array}$ & $\begin{array}{l}.015078 \\
.016368 \\
.016175 \\
.022252 \\
.010505\end{array}$ & $\begin{array}{l}.43444 \\
.27822 \\
.27816 \\
.23613 \\
.11034\end{array}$ & $\begin{array}{r}+.00028 \\
+.00015 \\
+.00015 \\
+.00013 \\
+.00015\end{array}$ & $\begin{array}{l}1 \\
1 \\
1 \\
1 \\
2\end{array}$ \\
\hline $\begin{array}{l}\text { Feb. } 15 \\
\text { Do } \\
\text { Feb. } 16 \\
\text { Do } \\
\text { Feb. } 17\end{array}$ & $\begin{array}{l}75.31 \\
75.31 \\
74.97 \\
74.91 \\
75.03\end{array}$ & $\begin{array}{r}10.332 \\
10.257 \\
9.926 \\
9.757 \\
5.029\end{array}$ & $\begin{array}{r}1.498 \\
1.498 \\
7.094 \\
7.098 \\
15.073\end{array}$ & $\begin{array}{l}.0287 \\
.0083 \\
.0105 \\
.0030 \\
.0134\end{array}$ & $\begin{array}{l}.021529 \\
.010159 \\
.027897 \\
.015206 \\
.061750\end{array}$ & $\begin{array}{l}.50044 \\
.23310 \\
.69682 \\
.37297 \\
.96117\end{array}$ & $\begin{array}{r}+.00031 \\
+.00029 \\
+.00030 \\
+.00032 \\
+.00015\end{array}$ & $\begin{array}{l}2 \\
2 \\
2 \\
1 \\
2\end{array}$ \\
\hline $\begin{array}{l}\text { Feb. } 18 \\
\text { Do } \\
\text { Feb. } 20 \\
\text { Do } \\
\text { Feb. } 24\end{array}$ & $\begin{array}{r}75.18 \\
75.08 \\
115.29 \\
115.26 \\
114.92\end{array}$ & $\begin{array}{r}10.258 \\
9.999 \\
10.234 \\
10.213 \\
9.583\end{array}$ & $\begin{array}{r}15.066 \\
10.419 \\
1.498 \\
7.101 \\
10.408\end{array}$ & $\begin{array}{l}.0013 \\
.0020 \\
.0098 \\
.0091 \\
.0075\end{array}$ & $\begin{array}{l}.014450 \\
.015370 \\
.009605 \\
.026055 \\
.028772\end{array}$ & $\begin{array}{l}.45553 \\
.41710 \\
.22446 \\
.64886 \\
.70052\end{array}$ & $\begin{array}{r}+.00029 \\
+.00030 \\
+.00046 \\
+.00036 \\
+.00048\end{array}$ & $\begin{array}{l}2 \\
2 \\
2 \\
2 \\
1\end{array}$ \\
\hline $\begin{array}{c}\text { Feb. } 25 \\
\text { Feb. } 27 \\
\text { Do } \\
\text { Feb. } 28 \\
\text { Do }\end{array}$ & $\begin{array}{l}115.06 \\
114.91 \\
114.70 \\
149.99 \\
150.06\end{array}$ & $\begin{array}{l}9.166 \\
9.699 \\
9.258 \\
9.894 \\
9.963\end{array}$ & $\begin{array}{r}7.103 \\
15.069 \\
10.400 \\
2.300 \\
2.300\end{array}$ & $\begin{array}{l}.0064 \\
.0033 \\
.0037 \\
.0260 \\
.0053\end{array}$ & $\begin{array}{l}.017632 \\
.026437 \\
.017906 \\
.021983 \\
.007815\end{array}$ & $\begin{array}{l}.39397 \\
.69227 \\
.42065 \\
.51240 \\
.18232\end{array}$ & $\begin{array}{r}+.00043 \\
+.00038 \\
+.00042 \\
+.00080 \\
+.00068\end{array}$ & $\begin{array}{l}1 \\
3 \\
2 \\
2 \\
3\end{array}$ \\
\hline $\begin{array}{l}\text { Mar. } 2 \\
\text { Do.- } \\
\text { Mar. } 3 \\
\text { Do } \\
\text { Do.... }\end{array}$ & $\begin{array}{l}150.03 \\
150.01 \\
150.05 \\
150.07 \\
149.97\end{array}$ & $\begin{array}{l}9.899 \\
9.876 \\
9.941 \\
9.981 \\
9.915\end{array}$ & $\begin{array}{r}2.299 \\
2.302 \\
4.030 \\
7.105 \\
10.408\end{array}$ & $\begin{array}{l}.0048 \\
.0261 \\
.0063 \\
.0027 \\
.0040\end{array}$ & $\begin{array}{l}.007808 \\
.022018 \\
.013890 \\
.011492 \\
.016862\end{array}$ & $\begin{array}{l}.18144 \\
.51281 \\
.32960 \\
.28023 \\
.41913\end{array}$ & $\begin{array}{r}+.00048 \\
+.00042 \\
-.00021 \\
-.00020 \\
-.00021\end{array}$ & $\begin{array}{l}2 \\
2 \\
3 \\
2 \\
2\end{array}$ \\
\hline $\begin{array}{l}\text { Mar. } 4 \\
\text { Do... } \\
\text { Mar. } 6 \\
\text { Do } \\
\text { Mar. } 7\end{array}$ & $\begin{array}{l}150.00 \\
150.07 \\
150.06 \\
150.05 \\
150.00\end{array}$ & $\begin{array}{l}9.894 \\
8.062 \\
9.742 \\
9.752 \\
9.862\end{array}$ & $\begin{array}{r}15.056 \\
15.051 \\
1.502 \\
10.386 \\
0.376\end{array}$ & $\begin{array}{l}.0040 \\
.0185 \\
.0101 \\
.0040 \\
.0273\end{array}$ & $\begin{array}{l}.024902 \\
.053977 \\
.009240 \\
.018431 \\
.007727\end{array}$ & $\begin{array}{r}.64250 \\
1.13722 \\
.21122 \\
.45076 \\
.17757\end{array}$ & $\begin{array}{r}-.00021 \\
-.00026 \\
-.00019 \\
-.00019 \\
-.00020\end{array}$ & $\begin{array}{l}2 \\
1 \\
2 \\
2 \\
2\end{array}$ \\
\hline $\begin{array}{l}\text { Do } \\
\text { Mar. } 9 \\
\text { Do } \\
\text { Do } \\
\text { Mar. } 10 . \\
\end{array}$ & $\begin{array}{r}150.01 \\
115.02 \\
114.97 \\
115.03 \\
75.02\end{array}$ & $\begin{array}{l}8.025 \\
9.715 \\
9.714 \\
9.750 \\
9.884\end{array}$ & $\begin{array}{r}15.049 \\
0.380 \\
4.054 \\
4.049 \\
0.377\end{array}$ & $\begin{array}{l}.0185 \\
.0277 \\
.0387 \\
.0065 \\
.0270\end{array}$ & $\begin{array}{l}.054030 \\
.008281 \\
.041328 \\
.014666 \\
.008789\end{array}$ & $\begin{array}{l}1.13194 \\
.18222 \\
.94935 \\
.33644 \\
.19157\end{array}$ & $\begin{array}{l}-.00025 \\
+.00036 \\
+.00036 \\
+.00036 \\
+.00030\end{array}$ & $\begin{array}{l}1 \\
2 \\
2 \\
2 \\
2\end{array}$ \\
\hline $\begin{array}{l}\text { Do } \\
\text { Mar. } 11 . \\
\text { Do. } \\
\text { Do } \\
\text { Mar. 17- }\end{array}$ & $\begin{array}{r}75.07 \\
93.19 \\
112.90 \\
113.02 \\
-0.03\end{array}$ & $\begin{array}{r}9.969 \\
10.071 \\
48.743 \\
48.787 \\
9.917\end{array}$ & $\begin{array}{r}4.037 \\
15.050 \\
1.498 \\
1.501 \\
2.300\end{array}$ & $\begin{array}{l}.0057 \\
.0056 \\
.0096 \\
.0043 \\
.0225\end{array}$ & $\begin{array}{l}.015635 \\
.028890 \\
.010022 \\
.005484 \\
.028313\end{array}$ & $\begin{array}{r}.36721 \\
.82798 \\
1.11540 \\
.61238 \\
.70683\end{array}$ & $\begin{array}{r}+.00030 \\
+.00032 \\
+.00067 \\
+.00067 \\
+.00018\end{array}$ & $\begin{array}{l}2 \\
2 \\
2 \\
2 \\
2\end{array}$ \\
\hline $\begin{array}{r}\text { Do } \\
\text { Mar. } 20 \ldots \ldots \\
\text { Do } \\
\text { Mar. } 21 \ldots \\
\end{array}$ & $\begin{array}{r}+0.06 \\
0.01 \\
0.12 \\
-15.13\end{array}$ & $\begin{array}{r}10.015 \\
9.804 \\
10.037 \\
5.937\end{array}$ & $\begin{array}{l}2.301 \\
0.380 \\
1.501 \\
0.382\end{array}$ & $\begin{array}{l}.0036 \\
.0235 \\
.0148 \\
.0230\end{array}$ & $\begin{array}{l}.010044 \\
.010075 \\
.018215 \\
.010435\end{array}$ & $\begin{array}{l}.25036 \\
.21166 \\
.42602 \\
.13484\end{array}$ & $\begin{array}{r}+.00021 \\
-.00034 \\
-.00035 \\
-.00017\end{array}$ & $\begin{array}{l}2 \\
2 \\
2 \\
2\end{array}$ \\
\hline
\end{tabular}


TABLE 4.-Calculation of $C_{\mathrm{p}}$

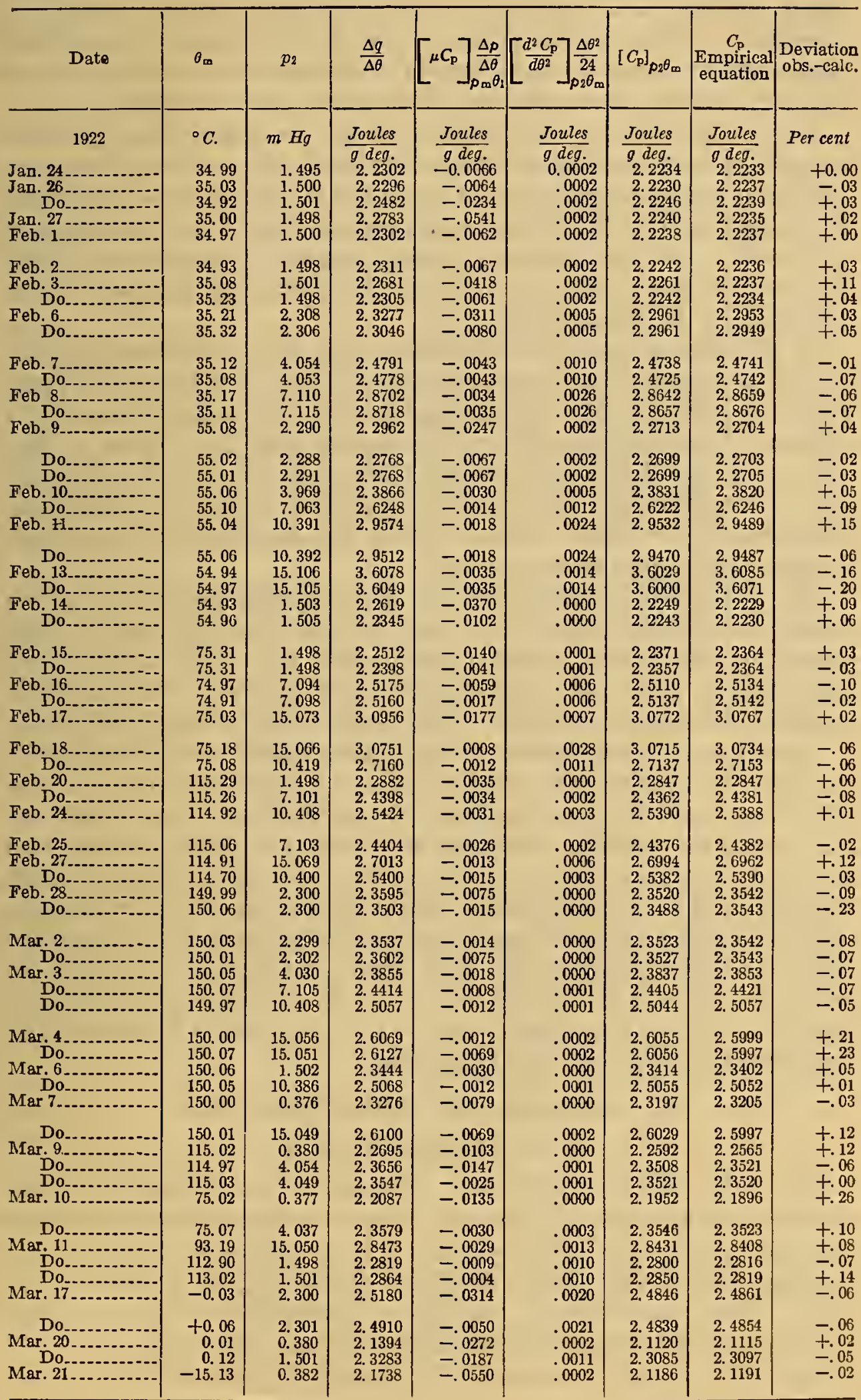


determination with a smaller flow. Upon this occasion good additional evidence was obtained of the presence of liquid within the calorimeter. The result obtained in the preceeding experiment was, therefore, open to considerable doubt, and as a consequence it has been excluded from the list of accredited determinations.

It is of interest to consider how we may explain the apparently anomalous phenomenon of liquefaction when the indicated temperature and pressure corresponded to superheated vapor. On account of the precautions to prevent entrained wetness in the vapor supply delivered to the calorimeter it seems certain that whatever liquid appeared in the calorimeter was formed during the approach of the ammonia to thermometer cell $T_{1}$.

In the passage from the calorimeter bath to thermometer cell, $T_{1}$, the vapor experiences a moderate pressure drop, but has little opportunity to absorb heat. It is plausible that the cooling effect of this pressure drop accentuated by regenerative back conduction of heat may have cooled part of the ammonia stream down to the temperature of liquefaction, and that the entrained liquid was carried on mechanically for some distance within the calorimeter before equilibrium could again be established.

This speculation is supported by the fact that indications of the presence of liquid were fairly abrupt upon close approach to the saturation limit, and tends to strengthen the belief that for the experiments where no irregularities were observed, the ammonia entering the calorimeter system was homogeneous superheated vapor.

Apart from casting doubt on this critical experiment of March 28, the effect of crowding the conditions too far was disastrous for it was found on the following day that the calorimeter heating coil was short circuited between windings producing a variable resistance in that coil. In an attempt to remove the cause of this short circuit by excessive heating of the coil, a leak developed in one of the soldered joints rendering the calorimeter unsuitable for further experimentation. Enough experimental data had already been obtained to establish a formula for the specific heat of the superheated vapor in the region of greatest importance, and so this unexpected termination of the series was accepted with resignation.

\section{RESULTS OF MEASUREMENTS}

\section{CALORIMETRIC DATA}

The data obtained from the calorimetric measurements of the specific heat are given in Table 3. The values given in each column represent, in most cases, average values obtained from several readings which were made during a determination of the rate of flow. When successive or duplicate experiments were made, only the averages of the various readings are given. The various observations taken during a single flow measurement constituted a complete determination. 
The results of all the accredited experiments are included in Table 3. Except for one experiment very close to the saturation limit, Table 3 contains the results of all the complete experiments performed in 1922. The data obtained in the experiments of 1921, all of which were discredited on account of the uncertainty of the thermal leakage correction, are given in Table 5. This table also contains the computations of the specific heat from those data. In the last experiment performed in 1922, the results of which are also given in Table 5 , the initial pressure and temperature were so close to the saturation limit that the results are considered doubtful.

The results of all the measurements on the Joule-Thomson coefficient, $\mu$, are given in Table 6 . The values given for $\Delta p, \Delta \theta$, and $N$ are the averages of several readings. The rate of flow was not measured in these experiments at the time the other readings were made. It was held sensibly constant and measured, in several instances, during the specific heat experiment which followed. The values designated "Flow not measured" were estimated from the observed fore pressure and the calibration of the particular orifice or orifices used.

The scale of temperature used in the measurements given in this paper is the scale defined by the resistance thermometer of pure platinum, standardized at the temperatures of melting ice $\left(0^{\circ} \mathrm{C}\right.$.), condensing steam $\left(100^{\circ} \mathrm{C}\right.$.), and condensing sulphur vapor $\left(444.6^{\circ} \mathrm{C}\right.$.), all at standard atmospheric pressure $\left(760 \mathrm{~mm}\right.$ of mercury at $0^{\circ} \mathrm{C}$. and standard gravity). Using the Callendar equation

$$
\theta=\frac{R_{\theta}-R_{\mathrm{o}}}{R_{100}-R_{\mathrm{o}}} 100+\delta\left(\frac{\theta}{100}-1\right) \frac{\theta}{100}
$$

as an interpolation equation, the scale so defined represents the thermodynamic scale in the interval -40 to $+450^{\circ} \mathrm{C}$. to the accuracy with which that scale is at present known. Temperatures on the absolute thermodynamic scale are obtained by adding $273.1^{\circ}$ to the measured temperature.

All of the pressure measurements have been reduced to meters of mercury at $0^{\circ} \mathrm{C}$. and at standard gravity $(g=980.665) .{ }^{14}$ The value of $g$ in this laboratory is 980.091 , based upon a determination made by the United States Coast and Geodetic Survey in 1910. ${ }^{15}$

The fundamental heat unit used in these measurements is the international joule, defined by the relation $\frac{Q}{t}=\frac{E^{2}}{R}$ where $Q$ is the number of joules transformed into heat in a given electric circuit in $t$ seconds, $E$ is the number of volts potential drop, and $R$ is the number

14 This value was adopted by the International Committee on Weights and Measures in 1901. (Travaur et Mémoires du Bur. Int., third general conference, p 66; 1902).

so B. S. Bulletin, 8, p. 363; 1912 (Sci. Paper No. 171). 
of ohms resistance; taking 1 volt $=\frac{1}{1.01830} \times$ emf of mean Weston normal cell at $20^{\circ}$, and $1 \mathrm{ohm}=$ resistance at $0^{\circ} \mathrm{C}$. of $106.300 \mathrm{~cm}$ mercury column of constant cross-sectional area and 14. 4521 in mass. The difference between the international joule, realized thus, and the absolute joule is about 1 part in 3,000, according to Bureau of Standards Circular No. 60, 2d edition (1920). The ampere is used only as an intermediary unit, being determined by the relation $I=\frac{E}{R}$. As a secondary heat unit the $20^{\circ}$ calorie, defined as 4.183 international joules, has been used in the table given in the appendix.

TABLE 5.-Discredited experiments

\begin{tabular}{|c|c|c|c|c|c|c|c|c|}
\hline Date & $\begin{array}{c}\text { Mean } \\
\text { temper } \\
\text { ature } \\
-\theta_{\text {m }}\end{array}$ & $\begin{array}{c}\text { Temper- } \\
\text { ature } \\
\text { rise } \\
\Delta \theta\end{array}$ & $\begin{array}{c}\text { Final } \\
\text { pressure } \\
p_{2}\end{array}$ & $\begin{array}{l}\text { Pressure } \\
\text { drop } \\
-\Delta p\end{array}$ & $\begin{array}{c}\text { Rate of } \\
\text { flow } \\
\qquad F\end{array}$ & $\begin{array}{l}\text { Power } \\
\text { EI }\end{array}$ & $\begin{array}{c}\text { Thermal } \\
\text { leakage } \\
(N-0.2 \Delta \theta) x\end{array}$ & $\begin{array}{l}\text { Num- } \\
\text { ber of } \\
\text { deter- } \\
\text { mina- } \\
\text { tions }\end{array}$ \\
\hline 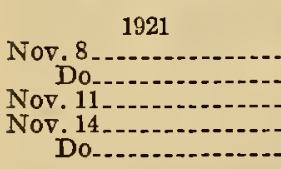 & $\begin{array}{l}{ }^{\circ} \mathrm{C} . \\
35.75 \\
35.40 \\
35.14 \\
34.91 \\
32.58\end{array}$ & \begin{aligned} & \multicolumn{1}{c}{$C} \multicolumn{1}{c}{10.997} \\
& 10.359 \\
& 9.382 \\
& 9.467 \\
& 4.865\end{aligned}$. & $\begin{array}{l}m H g \\
1.736 \\
1.744 \\
2.135 \\
2.076 \\
2.076\end{array}$ & $\begin{array}{l}m \mathrm{Hg} \\
0.0090 \\
.0320 \\
.0045 \\
.0210 \\
.0210\end{array}$ & $\begin{array}{l}\text { g/sec. } \\
0.012775 \\
.026875 \\
.008681 \\
.023695 \\
.023695\end{array}$ & $\begin{array}{l}\text { Watts } \\
0.31596 \\
.63181 \\
.18636 \\
.51414 \\
.26651\end{array}$ & $\begin{array}{c}\text { Watts } \\
-0.00062 \\
-.00081 \\
-.00062 \\
-.00061 \\
-.00036\end{array}$ & $\begin{array}{l}1 \\
1 \\
2 \\
1 \\
1\end{array}$ \\
\hline $\begin{array}{l}\text { Nov. } 16 \\
\text { Do } \\
\text { Nor. } 18 \\
\text { Do- } \\
\text { Nor. } 21\end{array}$ & $\begin{array}{l}+0.02 \\
+0.02 \\
-0.33 \\
+0.28 \\
15.10\end{array}$ & $\begin{array}{r}9.762 \\
9.739 \\
9.069 \\
10.255 \\
9.802\end{array}$ & $\begin{array}{l}2.450 \\
2.454 \\
2.453 \\
2.452 \\
1.474\end{array}$ & $\begin{array}{l}.0080 \\
.0070 \\
.0100 \\
.0110 \\
.0030\end{array}$ & $\begin{array}{l}.017215 \\
.017265 \\
.018813 \\
.018818 \\
.006168\end{array}$ & $\begin{array}{l}.42637 \\
.42641 \\
.43398 \\
.48950 \\
.13690\end{array}$ & $\begin{array}{l}-.00054 \\
-.00054 \\
-.00049 \\
-.00047 \\
-.00065\end{array}$ & $\begin{array}{l}1 \\
1 \\
1 \\
1 \\
1\end{array}$ \\
\hline $\begin{array}{r}\text { Nov. } 22 \\
\text { Nov. } 23 . \\
\text { Do } \\
\text { Nov. } 25 \\
\text { Do }\end{array}$ & $\begin{array}{l}15.55 \\
17.18 \\
15.08 \\
55.80 \\
55.89\end{array}$ & $\begin{array}{r}10.724 \\
14.050 \\
9.815 \\
11.120 \\
11.329\end{array}$ & $\begin{array}{l}\text { 1. } 101 \\
\text { 1. } 476 \\
2.538 \\
1.209 \\
2.491\end{array}$ & $\begin{array}{l}.0015 \\
.0025 \\
.0050 \\
.0040 \\
.0040\end{array}$ & $\begin{array}{l}.004567 \\
.006183 \\
.010812 \\
.004672 \\
.009815\end{array}$ & $\begin{array}{l}.10872 \\
.19597 \\
.25570 \\
.11535 \\
.25446\end{array}$ & $\begin{array}{l}-.00065 \\
-.00087 \\
-.00060 \\
-.00072 \\
-.00081\end{array}$ & $\begin{array}{l}2 \\
1 \\
2 \\
1 \\
1\end{array}$ \\
\hline $\begin{array}{l}\text { Nov. } 26 \ldots \\
\text { Do } 0 \\
\text { Nov. } 28 \\
\text { Do } 0 \\
\text { Nov. } 29\end{array}$ & $\begin{array}{r}-15.37 \\
-15.06 \\
55.50 \\
55.80 \\
0.36\end{array}$ & $\begin{array}{r}8.899 \\
9.455 \\
5.804 \\
6.381 \\
10.014\end{array}$ & $\begin{array}{l}1.198 \\
1.198 \\
1.196 \\
1.196 \\
1.188\end{array}$ & $\begin{array}{l}.0025 \\
.0025 \\
.0035 \\
.0035 \\
.0020\end{array}$ & $\begin{array}{l}.005308 \\
.005315 \\
.004578 \\
.004600 \\
.005117\end{array}$ & $\begin{array}{l}.11093 \\
.11774 \\
.05920 \\
.06529 \\
.11564\end{array}$ & $\begin{array}{l}-.00044 \\
-.00044 \\
-.00042 \\
-.00046 \\
-.00054\end{array}$ & $\begin{array}{l}1 \\
1 \\
1 \\
1 \\
1\end{array}$ \\
\hline $\begin{array}{l}\text { Nov, } 30 \\
\text { Do } \\
\text { Do } \\
\text { Dec. } 1 \\
\text { Do }\end{array}$ & $\begin{array}{r}0.30 \\
0.31 \\
0.19 \\
34.90 \\
34.76\end{array}$ & $\begin{array}{r}9.966 \\
10.025 \\
9.798 \\
9.453 \\
9.164\end{array}$ & $\begin{array}{l}1.190 \\
1.889 \\
1.889 \\
1.098 \\
2.492\end{array}$ & $\begin{array}{l}.0030 \\
.0030 \\
.0030 \\
.0025 \\
.0035\end{array}$ & $\begin{array}{l}.005108 \\
.008241 \\
.008240 \\
.004392 \\
.010218\end{array}$ & $\begin{array}{l}.11520 \\
.19795 \\
.19354 \\
.09177 \\
.21758\end{array}$ & $\begin{array}{l}-.00060 \\
-.00054 \\
-.00050 \\
-.00060 \\
-.00058\end{array}$ & $\begin{array}{l}1 \\
1 \\
1 \\
2 \\
2\end{array}$ \\
\hline $\begin{array}{l}\text { Dec. } 2 \\
\text { Doo. } \\
\text { Dec. } 3 \\
\text { Do }\end{array}$ & $\begin{array}{l}\text { 34. } 07 \\
34.15 \\
34.17 \\
34.15\end{array}$ & $\begin{array}{l}7.905 \\
7.923 \\
7.946 \\
7.918\end{array}$ & $\begin{array}{l}1.457 \\
1.474 \\
1.465 \\
1.465\end{array}$ & $\begin{array}{l}.0400 \\
.0030 \\
.0030 \\
.0070\end{array}$ & $\begin{array}{l}.028142 \\
.005924 \\
.005909 \\
.009788\end{array}$ & $\begin{array}{l}.50280 \\
.10511 \\
.10539 \\
.17337\end{array}$ & $\begin{array}{l}-.00052 \\
-.00052 \\
-.00052 \\
-.00052\end{array}$ & $\begin{array}{l}1 \\
1 \\
1 \\
1\end{array}$ \\
\hline 1922 & & & & & & & & \\
\hline Mar. 28 & -15.00 & 6.012 & 1.484 & .0140 & .017395 & .25957 & -.00000 & 2 \\
\hline
\end{tabular}


TABLE 5.-Discredited experiments-Continued

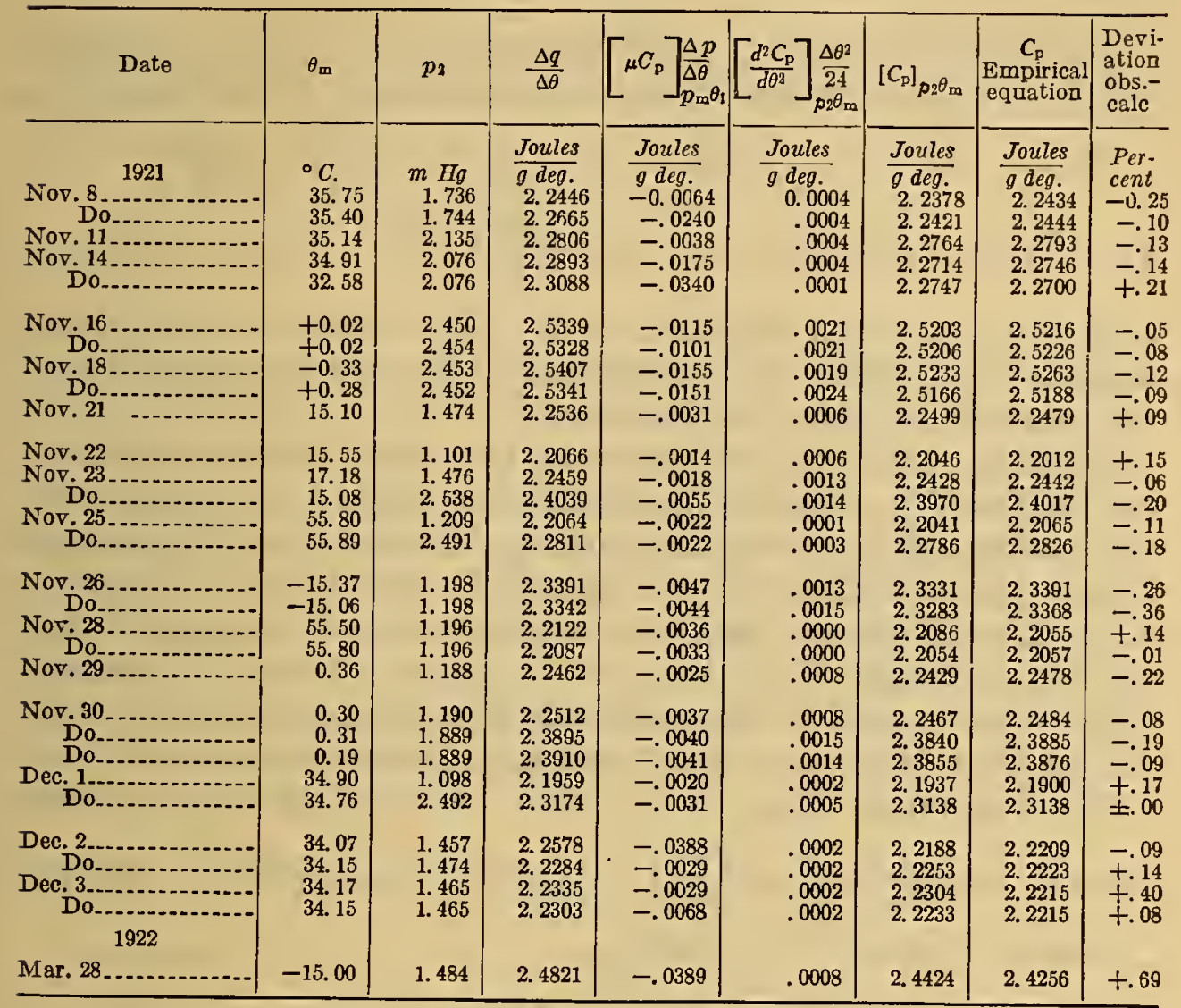

TABLE 6.-Joule-Thomson data

\begin{tabular}{|c|c|c|c|c|c|c|c|c|c|c|c|c|c|c|}
\hline Date & $\mid \begin{array}{c}\text { Mean } \\
\text { tem- } \\
\text { pera- } \\
\text { ture } \\
\theta_{\mathrm{m}}\end{array}$ & $\left|\begin{array}{c}\text { Mean } \\
\text { pres- } \\
\text { sure } \\
p_{\text {xus }}\end{array}\right|$ & $\begin{array}{l}\text { Spe- } \\
\text { ciffc } \\
\text { heat } \\
C_{\mathrm{p}}\end{array}$ & $\begin{array}{l}\text { Rate } \\
\text { of } \\
\text { fow } \\
F\end{array}$ & $\mid \begin{array}{c}\text { Regu- } \\
\text { lating } \\
\text { coul- } \\
\text { ple } \\
N\end{array}$ & $\begin{array}{l}\text { Tem- } \\
\text { per- } \\
\text { ature } \\
\text { drop } \\
-\Delta \theta\end{array}$ & $\begin{array}{l}\text { Pres- } \\
\text { sure } \\
\text { drop } \\
-\Delta p\end{array}$ & $\frac{\Delta \theta}{\Delta p}$ & $\begin{array}{c}\text { Leak- } \\
\text { age } \\
\text { cor- } \\
\text { rec- } \\
\text { tion } \\
\quad \mathrm{X} \\
C_{\mathrm{p}} F \Delta p\end{array}$ & $\mu$ & $\mu C_{\mathrm{p}}$ & $\left|\begin{array}{c}\text { Equa- } \\
\text { tion } \\
\mu C_{\mathrm{p}}\end{array}\right|$ & $\mid \begin{array}{l}\text { Devi- } \\
\text { ation } \\
\text { obs.- } \\
\text { calc. }\end{array}$ & $\begin{array}{c}\text { Devi- } \\
\text { ation } \\
\text { ex- } \\
\text { pressed } \\
\text { in- }\end{array}$ \\
\hline & & & $\frac{\text { Joules }}{\text { odeg }} \mid$ & & & & & $\frac{D e g .}{m \nabla n}$ & Deg. & Deg. & & Joules & $\mathrm{Per}$ & \\
\hline Nov. 9 & $\begin{array}{l}30.16 \\
30.11\end{array}$ & \begin{tabular}{|l|}
$m H g$ \\
1.760 \\
1.815
\end{tabular} & $\begin{array}{l}\text { gdeg. } \\
2.252 \\
2.257\end{array}$ & \begin{tabular}{|l} 
g/sec. \\
0.027 \\
1.035
\end{tabular} & $\begin{array}{c}\mu v \\
-0.1 \\
+0.5\end{array}$ & $\mid \begin{array}{l}0 . C \\
0.103 \\
.154\end{array}$ & $\left|\begin{array}{l}m \mathrm{Hg} \\
0.0300 \\
.0453\end{array}\right|$ & $\begin{array}{r}m \mathrm{HIg} \\
3.43 \\
3.40\end{array}$ & $\begin{array}{c}m H g \\
-0.01 \\
+.05\end{array}$ & $\begin{array}{r}\mathrm{mHg} \\
3.42 \\
3.45\end{array}$ & $\begin{array}{r}m \mathrm{mg} \\
7.70 \\
7.79\end{array}$ & \begin{tabular}{|r|}
$\mathrm{mHg}$ \\
7.78 \\
780
\end{tabular} & $\mid \begin{array}{l}\text { cent } \\
-1.0 \\
-0.1\end{array}$ & $\begin{array}{r}{ }^{\circ} C \\
-0.001 \\
-0000\end{array}$ \\
\hline & $\begin{array}{r}30.15 \\
-5.35\end{array}$ & $\left|\begin{array}{c}2.308 \\
2 \\
307\end{array}\right|$ & $\mid \begin{array}{l}2.308 \\
2553\end{array}$ & $\begin{array}{l}1 \\
1 \\
1\end{array}$ & +0.5 & .241 & $\begin{array}{l}.0723 \\
0826\end{array}$ & $\begin{array}{l}3.37 \\
3.37\end{array}$ & $\begin{array}{r}+.02 \\
+.02 \\
.03\end{array}$ & $\begin{array}{r}3.39 \\
5.51\end{array}$ & 7.82 & $\left|\begin{array}{r}7.96 \\
7.96\end{array}\right|$ & $\mid \begin{array}{r}1.8 \\
1.8\end{array}$ & $\begin{array}{l}-.000 \\
-.004\end{array}$ \\
\hline & $\begin{array}{r}-4.98 \\
+52.49\end{array}$ & 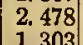 & \begin{tabular}{|l|}
2.584 \\
2.208
\end{tabular} & .01593 & $\begin{array}{l}-1.0 \\
+0.5\end{array}$ & $\begin{array}{l}.400 \\
.038 \\
090\end{array}$ & .075 & 5. 07 & $\begin{array}{r}-. .3 \\
+.40 \\
\end{array}$ & $\begin{array}{l}5.04 \\
5.47\end{array}$ & $\begin{array}{l}14.14 \\
14.19\end{array}$ & $\left|\begin{array}{l}14.03 \\
14.12\end{array}\right|$ & $\begin{array}{l}+0.8 \\
+0.5\end{array}$ & $\begin{array}{r}+.004 \\
.000\end{array}$ \\
\hline & & & & & & & & & & 2.60 & 0.90 & 0.90 & +0.2 & \\
\hline $\begin{array}{l}\text { Jan. } 27 \\
\text { Feb. }\end{array}$ & $\begin{array}{l}30.09 \\
30.10\end{array}$ & $\begin{array}{l}\text { 1. } 532 \\
\text { 1. } 527\end{array}$ & $\left|\begin{array}{l}2.230 \\
2.230\end{array}\right|$ & $\begin{array}{l}.03877 \\
.03322\end{array}$ & $\begin{array}{r}0.0 \\
-2.0\end{array} \mid$ & $\begin{array}{l}.236 \\
.185\end{array}$ & \begin{tabular}{|l}
.0680 \\
.0525
\end{tabular} & $\begin{array}{l}3.47 \\
3.52\end{array}$ & $\begin{array}{r}.00 \\
-.13\end{array}$ & 3. 47 & 7.74 & 7.70 & +0.5 & $\begin{array}{r}+.001 \\
-.003\end{array}$ \\
\hline & $\begin{array}{l}30.17 \\
30.23\end{array}$ & $\begin{array}{l}2.326 \\
4\end{array}$ & \begin{tabular}{|c|c|c|}
2.314 \\
2.51
\end{tabular} & . 03591 & $\left|\begin{array}{r|}-0.1 \\
1\end{array}\right|$ & .133 & .0370 & 3. 59 & -.01 & 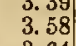 & $\begin{array}{l}7.56 \\
8.28\end{array}$ & $\begin{array}{l}7.70 \\
7.97\end{array}$ & +3.9 & \\
\hline & & 7.110 & | 2.964 & | & -0.1 & 012 & $\begin{array}{l}.0032 \\
: 0032\end{array}$ & & & $\begin{array}{l}\begin{array}{l}3.64 \\
3.58\end{array} \\
3\end{array}$ & $\begin{array}{r}9.14 \\
10.61\end{array}$ & $\begin{array}{l}8.55 \\
0.70\end{array}$ & $\begin{array}{r}+8.1 \\
+9.4\end{array}$ & +.0 \\
\hline & 49.98 & 2. 308 & 2.275 & .03439 & 0.0 & 108 & 0388 & 2.78 & 00 & 2.78 & 6.32 & 6.26 & +10 & +001 \\
\hline & $\begin{array}{l}52.52 \\
70.05\end{array}$ & $\begin{array}{l}1.5518 \\
1.513\end{array} \mid$ & $\left|\begin{array}{|l|}2.223 \\
2.232\end{array}\right|$ & . 02225 & +0.2 & .079 & 0284 & 2.78 & +.04 & 2. 82 & 6.27 & 6.00 & +4.5 & \\
\hline & & & & 027 & 0.0 & .052 & 0304 & $\begin{array}{l}1.71 \\
1.71\end{array}$ & & $\begin{array}{l}2.41 \\
1.71\end{array}$ & $\begin{array}{l}0.58 \\
3 \\
3.90\end{array}$ & 0.00 & +6.5 & \\
\hline & 110. & & & 030 & & 021 & 0118 & i. & & 1.70 & 4.33 & 3. 87 & $\begin{array}{r}+11.9 \\
+11.9\end{array}$ & $\begin{array}{r}+.04 \\
+.002\end{array}$ \\
\hline & 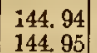 & $\begin{array}{l}2.323 \\
0.752\end{array}$ & $\begin{array}{l}2.347 \\
2.317\end{array}$ & $\begin{array}{l}1 \\
1 \\
1\end{array} .032$ & $\begin{array}{l}0.0 \\
0.0\end{array}$ & .053 & $\mid \begin{array}{r}0428 \\
0.448\end{array}$ & 1. 24 & .00 & 1. 24 & 2. 91 & $\begin{array}{l}2.85 \\
2.84\end{array}$ & +2 &.+ \\
\hline 20 & $\begin{array}{r}-5.02 \\
-18\end{array}$ & 0.392 & 2. 117 & $\begin{array}{r}.01007 \\
\end{array}$ & $\begin{array}{r}+0.9 \\
+0.9\end{array}$ & .118 & .0231 & 5.11 & $\begin{array}{r}+.00 \\
+\quad 28 \\
\end{array}$ & $\begin{array}{l}1.25 \\
5.39\end{array}$ & 11. 41 & $\begin{array}{r}\mid .84 \\
11.38\end{array} \mid$ & +0 & $\begin{array}{r}+.000 \\
.000\end{array}$ \\
\hline & & $0.59 \pm$ & & & -0.8 & & 0481 & & $\begin{array}{r}+.03 \\
-.03\end{array}$ & $\begin{array}{l}0.81 \\
6.19\end{array}$ & $\begin{array}{l}14.88 \\
15.16\end{array}$ & $\begin{array}{l}14.22 \\
15.02\end{array}$ & $\begin{array}{l}+2.5 \\
+0.8\end{array}$ & $\begin{array}{r}+.004 \\
+.003\end{array}$ \\
\hline
\end{tabular}

1 Flow not measured. 


\section{COMPUTATION OF RESULTS}

The computations of the specific heat, $C_{\mathrm{p}}$, are given in Tables 4 and 5. These computations are made according to the equation (13),

$$
\left[C_{\mathrm{p}}\right]_{p_{2} \theta_{\mathrm{m}}}=\frac{E I+(N-0.2 \Delta \theta) x}{F \Delta \theta}+\left[\mu C_{\mathrm{p}}\right]_{p_{\mathrm{m}} \theta_{1}} \frac{\Delta p}{\Delta \theta}-\left(\frac{\partial^{2} C_{\mathrm{p}}}{\partial \theta^{2}}\right)_{\mathrm{p} \theta_{\mathrm{m}}} \frac{\Delta \theta^{2}}{24}
$$

The value of the correction term $\left(\frac{\partial^{2} C_{\mathrm{p}}}{\partial \theta^{2}}\right) \frac{\Delta \theta^{2}}{24}$ is, in every case, less than 0.1 per cent of the final result. The terms involving higher orders of derivatives have been omitted because their effect upon the result is less than 0.01 per cent.

Equation (11) is used in computing the values of the Joule-Thomson coefficient, $\mu$. Since values of $\mu C_{\mathrm{p}}$ are required in equation (13), the products of the observed values of $\mu$ and interpolated values of $C_{\mathrm{p}}$ are given, in Table 6 , and compared with computed values of $\mu C_{\mathrm{p}}$. The differences between the observed and computed values of $\mu C_{\mathrm{p}}$, although rather large in percentage, correspond to only $0.005^{\circ} \mathrm{C}$. or less in the measurement of $\mu$, which is comparable with the accuracy attained in the calibration of the thermometers.

The computed values of $\mu C_{\mathrm{p}}$ were obtained, by means of the general relation $\mu C_{\mathrm{p}}=\theta\left(\frac{\partial v}{\partial \theta}\right)_{\mathrm{p}}-v$, from the following empirical "equation of state" for ammonia,

$$
v=\frac{R \theta}{p}-\frac{A}{\theta^{3}}-\frac{B p+C}{\theta^{11}}-\frac{D p^{5}}{\theta^{19}}-E+\theta \cdot f(p)
$$

in which $v$ is expressed in $\mathrm{cm}^{3} / \mathrm{g}, p$ in atmospheres, and $\theta$ in ${ }^{\circ} \mathrm{C}$. (abs), and

$$
\begin{array}{rlrl}
R & =4.8187 & C & =3.6934 \times 10^{26} \\
A & =3.40645 \times 10^{8} & D & =7.1166 \times 10^{40} \\
B & =3.2820 \times 10^{26} & E & =2.6000 \\
f(p) & =\left(5955.66-528.45 p+24.589 p^{2}-0.3538 p^{3}\right) 0.10-{ }^{\circ}
\end{array}
$$

This equation is not only in agreement with experimental results on $p, v, \theta$ within their estimated limit of accuracy, but is thermodynamically consistent with equations representing experimental results on other properties of the vapor, notably $C_{\mathrm{p}}$, and $H$ at saturation. It was developed for the purpose of computing tables of thermodynamic properties of ammonia, given in Bureau of Standards Circular No. 142, which contains the same equation in engineering units. The constants in the equation were derived, in part, from the empirical equation for $C_{\mathrm{p}}$ given in this paper, and, in part, from the saturation data and unpublished data on the specific 
volume of the superheated vapor obtained at this bureau. The last two or three digits in most of the constants are insignificant in computations of $v$ to an accuracy of 1 part in 1,000, but they become significant if the equation is used in computing other properties.

The derived equation for $\mu C_{\mathrm{p}}$ is

$$
{ }_{\mu} C_{p}=\frac{1.816 \times 10^{3}}{\theta^{3}}+\frac{(5.91+5.25 p) 10^{26}}{\theta^{11}}+\frac{1.90 p^{5} \times 10^{41}}{\theta^{19}}+0.347
$$

where $\mu C_{p}$ is expressed in joules per gram per meter of mercury, $p$ in atmospheres, and $\theta$ in degrees absolute $\left({ }^{\circ} \mathrm{C} .+273.1^{\circ}\right)$. The curves shown in Figure 8 represent values computed from this equation and the circles represent observed values of $\mu C_{p}$. Since the equation is in fair agreement with the experimental results on $\mu$, and since determinations of $\mu$ were not made at each of the states desired, all values of $\mu C_{p}$ used in the computation of $C_{p}$ were computed from the above equation or, in reality, obtained from the original drawing of Figure 8.

Values of the thermal leakage coefficient, $x$, were obtained from Figure 6. The upper line in Figure 6 was assumed for all the computations in Table 5.

\section{FORIM OF EMPIRICAL EQUATION}

An empirical equation of the form, $C_{p}=f(p, \theta)$, was chosen for two reasons, (1) because that form is most convenient for correlating the specific heat and specific volume measurements by means of the Clausius equation

$$
\left(\frac{\partial C_{\mathbf{p}}}{\partial p}\right)_{\theta}=-\theta\left(\frac{\partial^{2} v}{\partial \theta^{2}}\right)_{\mathbf{p}}
$$

and (2) because the final results of the experiments yield values of $C_{p}$ at definite pressures and temperatures. A form of the function, $f(p, \theta)$ was sought which would represent the experimental results closely and which could be handled easily as regards differentiation and integration.

For use over an extended range, the equation should satisfy the conditions that $C_{p}$ become infinite at the critical point and that the heat added for any finite temperature change be finite.

An equation which satisfied these conditions and at the same time gave the proper form for $v$ at the critical point would probably be very complex. Since the desired equation and others derivable in part from it, were to be used in computing a table of the properties of superheated ammonia vapor which covered only the range of the experiments, it seemed preferable to make the equation as simple as 
possible and not attempt to satisfy the conditions at the critical point.

A first approximation for the function, $f(p, \theta)$, was obtained from a simple "equation of state," similar to the one used by Callendar ${ }^{18}$ for steam, namely,

$$
v=\frac{R \theta}{p}-\frac{A}{\theta^{3}}
$$

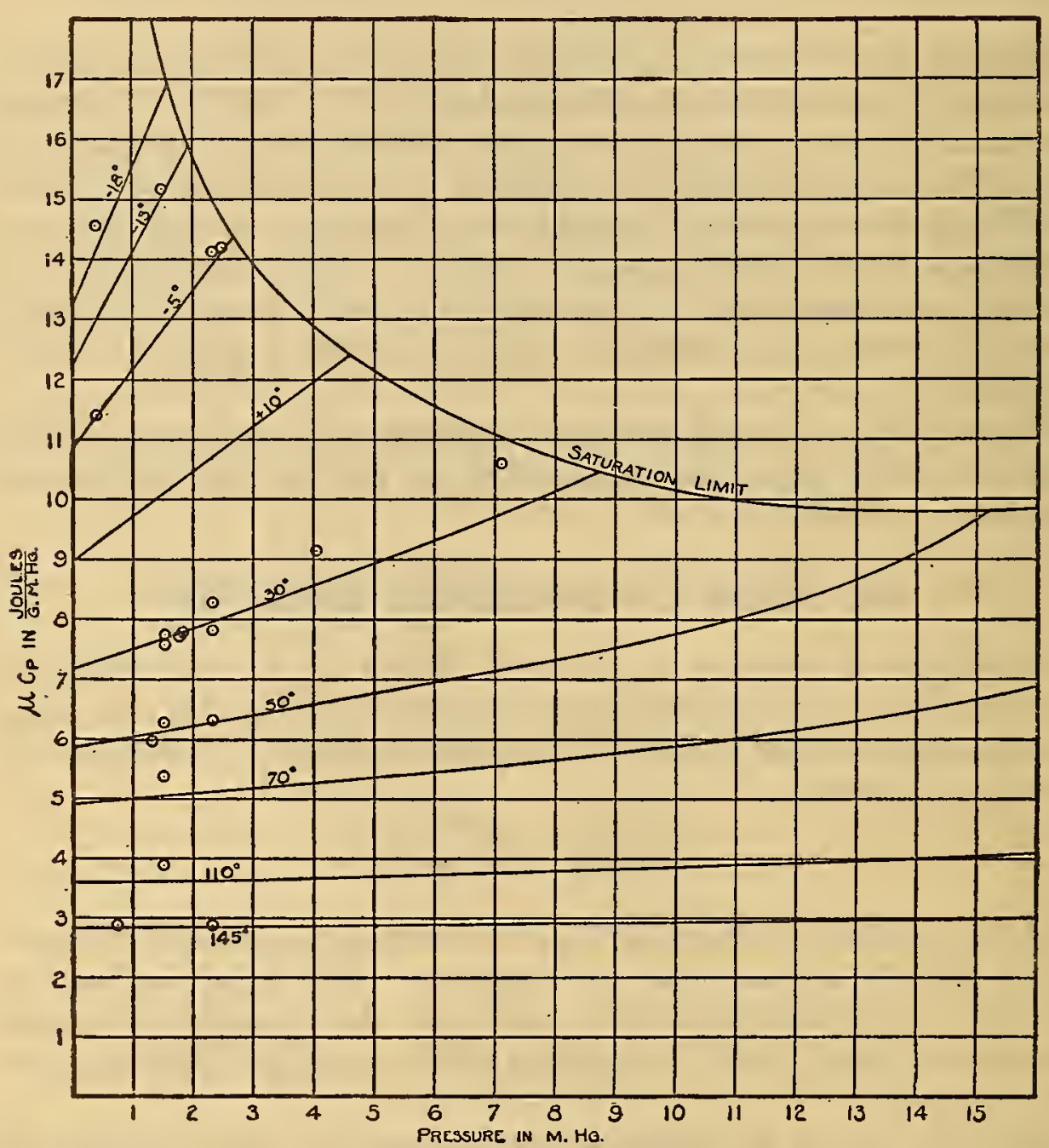

Fia. 8.-Comparison of observed values of Joule-Thomson effect, $\mu C^{2}$, for ammonia vapor with curves calculated from empirical equation

which was found to represent the experimental results on the specific volume within about 0.5 per cent. This equation when taken in conjunction with the Clausius equation, gave an equation of the form

$$
C_{\mathrm{p}}=C_{\mathrm{p}_{0}}+\frac{A^{\prime} p}{\theta^{4}}
$$

10 "Thermodynamical Properties of Gases and Vapors," Proc. Royal Society (London), 67A, p. 266;, 1900. Also "Properties of Steam," Longmans, Green \& Co., London; 1920. 
where $C_{\mathbf{p}_{0}}$ represents the limiting values of the specific heat at zero pressure, and is a function of temperature only.

The extrapolation of the experimentally determined isothermals of Figure 10 to zero pressure, gives values of $C_{\mathrm{p} 0}$ which bear approximately a linear relation to the temperature, but are more closely represented by a function of the form

$$
C_{\mathrm{p} 0}=A+B \theta+\frac{G}{\theta}
$$

Using then as an approximate equation

$$
C_{\mathbf{p}}=A+B \theta+\frac{C}{\theta}+\frac{D p}{\theta^{4}}
$$

and operating on the residuals, it was found necessary to use two additional terms in order to fit the results in the neighborhood of the saturation limit.

The form finally adopted to represent the results of the present investigation is

$$
C_{\mathbf{p}}=A+B \theta+\frac{C}{\theta}+\frac{D p}{\theta^{4}}+\frac{p(E+F p)}{\theta^{12}}+\frac{G p^{6}}{\theta^{20}}
$$

An equation, somewhat similar in form, has been found by .Eichelberg ${ }^{17}$ to represent well the experimental results on the specific heat of steam.

\section{DISCUSSION OF RESULTS}

The aggregate result of the entire series of determinations is represented by the following empirical equation:

$C_{\mathbf{p}}=1.1255+0.00238 \theta+\frac{76.8}{\theta}+\frac{5.45 p 10^{8}}{\theta^{4} .}+\frac{p(6.5+3.8 p) 10^{27}}{\theta^{12}}+\frac{2.37 p^{6} 10^{42}}{\theta^{20}}$

where $C_{\mathrm{p}}$ is expressed in joules per gram per degree centigrade, $p$ in meters of mercury at $0^{\circ} \mathrm{C}$. and standard gravity, and $\theta$ in degrees absolute $\left({ }^{\circ} \mathrm{C} .+273.1^{\circ}\right)$. The agreement between observed values of $C_{\mathrm{p}}$ and values computed from this equation is shown in Tables 4 and 5 .

It may be noted that Table 4 contains the results of 108 complete experiments which give the value of the specific heat at 35 points in the pressure temperature range. These experiments were purposely made at chosen pressures and temperatures for convenience in the analysis and each point was established by two or more experiments. By interpolating over small intervals of temperature and pressure,

17 “Zur Thermodynamik des Wasserdampfes," Zeitschrift des Vereines Deutsher Ingenieure, 61, p. 750; 1917. 
the results were corrected to seven temperatures $(-15,0,35,55,75$, 115 , and $150^{\circ}$ C.) and seven pressures $(0.38,1.5,2.3,4.05,7.1,10.4$, and $15.1 \mathrm{~m} \mathrm{Hg}$ ). The average result at each point was used in

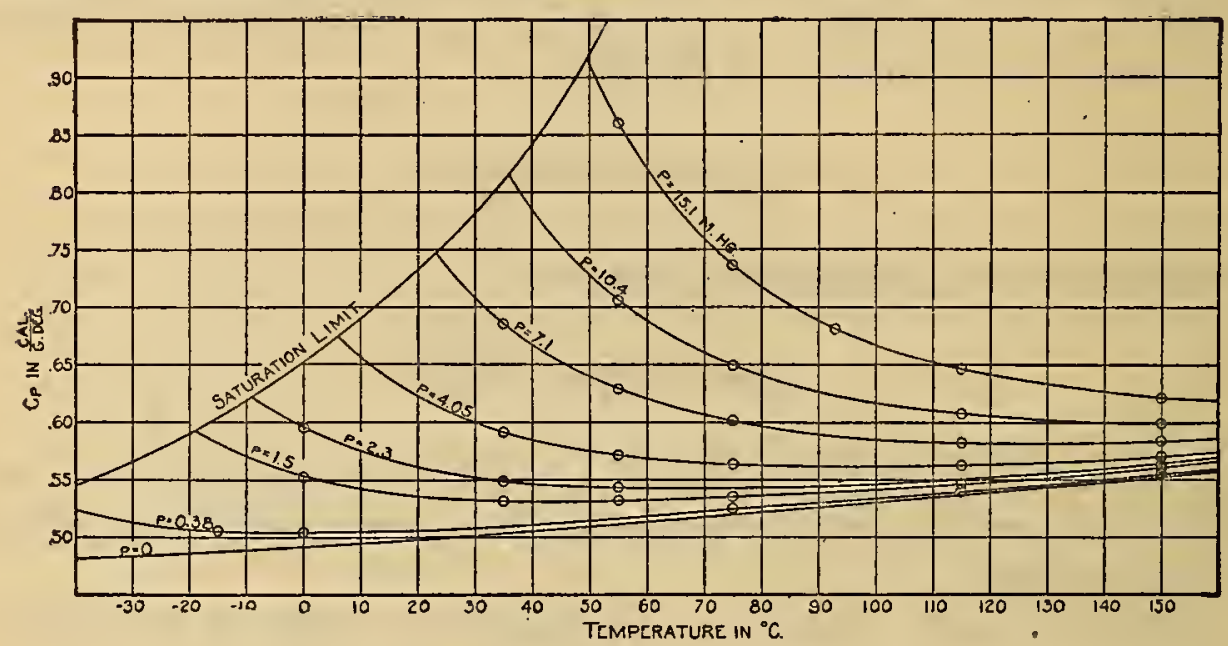

FIg. 9.-Specific heat of ammonia vapor at constant pressure

determining the constants in the empirical equation. The results at the 35 distinct points are shown graphically in Figures 9 and 10 with temperature and pressure, respectively, as the abscissas. The con-

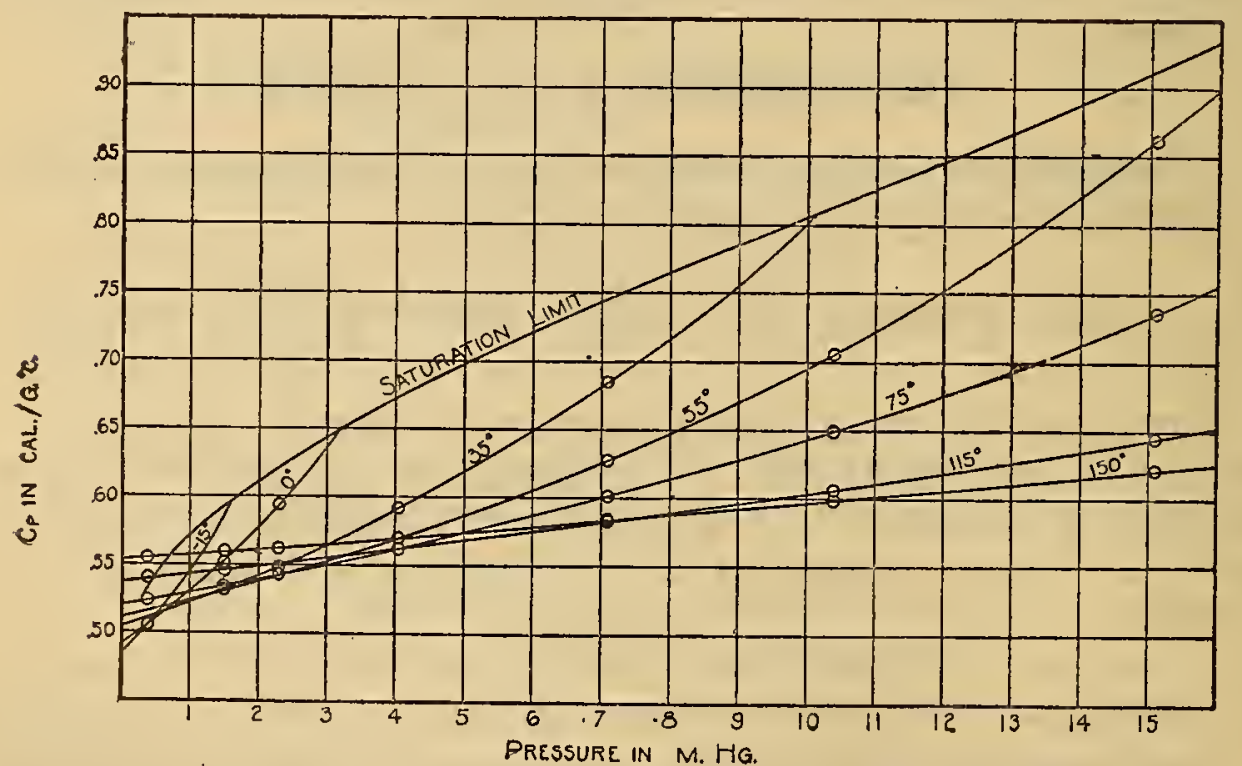

FIG. 10.-Specific heat of ammonia vapor at constant pressure

stant pressure and constant temperature lines represent values computed from the empirical equation and the circles, experimental determinations. The saturation limit of $C_{p}$ is obtained by extrapola- 
tion and is determined by the empirical equation taken simultaneously with the empirical equation for the vapor pressure.$^{18}$

It may be noted in Table 3 that the experimental conditions were varied considerably in the various experiments. For example, experiments were made with temperature rises of approximately 5 , 10 , and $50^{\circ}$, and with rates of flow which varied by a factor of 4 . These variations were introduced in order to note their effect upon the result and to detect sources of systematic errors. By examination of the deviations from the values given by the empirical equation it has not been possible to detect any systematic error.

An estimate of the accuracy of the measurements may be obtained by assigning average and maximum errors to each element which enters into the final result. Table 7 contains a tabulation of the magnitudes of these errors, which were estimated from the experience gained in making the measurements. They apply particularly to experiments with $10^{\circ}$ temperature rise. The agreement between the observed and estimated average errors indicates that the empirical equation fits the results, to about the estimated precision attained in the measurements. It will be noted that the maximum deviation from the equation is less than the estimated maximum error, which means that all of the possible errors were probably not cumulative in any single experiment.

TABLE 7.-Estimation of errors

[All errors are expressed in per cent produced in the final result, $C_{\mathrm{p}}$ ]

\begin{tabular}{|c|c|c|}
\hline Source of error & $\begin{array}{l}\text { A verage } \\
\text { error }\end{array}$ & $\underset{\text { error }}{\text { Maximum }}$ \\
\hline 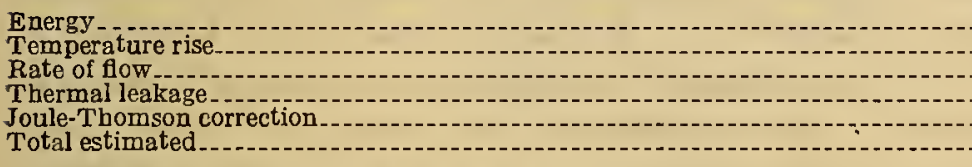 & $\begin{array}{r} \pm 0.02 \\
.05 \\
.05 \\
.03 \\
.02 \\
\pm .05\end{array}$ & $\begin{array}{r} \pm 0.05 \\
.15 \\
.15 \\
.10 \\
.10 \\
\pm .55\end{array}$ \\
\hline Observed deviations from empirical equation & 土. 07 & \pm .26 \\
\hline
\end{tabular}

\section{PREVIOUS DETERMINATIONS}

Previous determinations of the specific heat of ammonia vapor are few in number and have been limited to determinations at one atmosphere pressure. A summary of these determinations is given in Table 8, which contains also a comparison with the present results within the temperature range of the latter.

13 B. S. Sci. Papers, 16, p. 1; 1920 (Sci. Paper No. 369). Also in A. S. R. E. Jour., 6, p. 307; 1920, and in J. Am. Chem. Soc., 42, p. 206; 1919. 
TABLE 8.-Previous experimental determinations of $C_{\mathrm{D}}$ at one atmosphere pressure

\begin{tabular}{|c|c|c|c|c|c|c|c|}
\hline Date & Observer & $\begin{array}{l}\text { Number } \\
\text { of ob- } \\
\text { serva- } \\
\text { tions }\end{array}$ & $\begin{array}{c}\text { Temper- } \\
\text { ature } \\
\text { range }\end{array}$ & $\begin{array}{l}\text { Mean } \\
\text { temper- } \\
\text { ature }\end{array}$ & 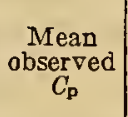 & $\begin{array}{c}\text { Maximum } \\
\text { deviation } \\
\text { from } \\
\text { mean }\end{array}$ & $\begin{array}{l}\text { Deviation from } \\
\text { present results }\end{array}$ \\
\hline $\begin{array}{l}1862 \ldots \ldots \\
1876 \ldots \ldots \\
1876 \ldots \ldots \\
1910 \ldots \ldots \\
1910 \ldots \ldots \\
1915 \ldots \ldots \\
1915 \ldots \ldots \\
1915 \ldots \ldots \\
1915 \ldots \ldots\end{array}$ & $\begin{array}{l}\text { Regnault 1 } \\
\text { Wiedemann }{ }^{2} \\
\text { Nernst }{ }^{2} \\
\text { Haber and Tamaru }\end{array}$ & $\begin{array}{r}2 \\
12 \\
11 \\
4 \\
2 \\
4 \\
6 \\
3 \\
4\end{array}$ & $\begin{array}{l}{ }^{\circ} C . \\
24-216 \\
25-100 \\
25-200 \\
365-569 \\
480-680 \\
219-401 \\
337-508 \\
337-508 \\
440-605\end{array}$ & $\begin{array}{l}{ }^{\circ} C . \\
120 \\
62.5 \\
112.5 \\
467 \\
580 \\
310 \\
422 \\
423 \\
523\end{array}$ & $\begin{array}{l}0.5084 \\
.5202 \\
.5356 \\
.605 \\
.658 \\
.605 \\
.646 \\
.646 \\
.693\end{array}$ & $\begin{array}{r}\text { Per cent } \\
0.2 \\
2.3 \\
2.6 \\
5.3 \\
1.8 \\
.4 \\
1.9 \\
.4 \\
.9\end{array}$ & $\begin{array}{ll}\text { Per cent } & \\
& -7.0 \\
-.6 & -.9 \\
\text { Arrangement } & \mathrm{B} . \\
\text { Arrangement } & \mathrm{A} . \\
\text { Arrangement } & \mathrm{B} . \\
\text { Arrangement } & \mathrm{B} .\end{array}$ \\
\hline
\end{tabular}

1 Mémoires de L'Acadamie des Sciences, II, p. 161; 1862.

2 Pogg. Ann. 157, p. 1; 1876.

Zeit. für Elektrochernie, 16, p. 96; 1910.

Zeit. für Elektrochemie, 21, p. 228; 1915.

Regnault and also Wiedemann used a method which consisted essentially of passing the heated vapor through a water calorimeter and observing the rate of flow of the vapor and the rise in temperature of the water. Their results on ammonia are in accord with their results on other gases and vapors in being systematically lower by a few per cent in general than those obtained by later experiments.

Nernst employed a comparative method in which various vapors passed through a preheater and then through a silver block which was inclosed in an electric furnace at a higher temperature. Adopting previously determined values of the specific heat of water vapor and carbon dioxide, he computed the specific heat of ammonia vapor from the observed rates of flow and the lowering of the temperature of the silver block. It may be remarked incidentally that the values of the specific heat adopted as standards are several per cent lower than those recently compiled by Holborn, Scheel, and Henning. ${ }^{19}$ The variations in the experimental conditions were not sufficient to warrant an estimate of the accuracy of the results, although in the one case in which the rate of flow was doubled approximately an apparent increase of 10 per cent in the value of the specific heat was observed. Tests were made which indicated that no appreciable decomposition of the ammonia vapor took place at the temperatures used.

Haber and Tamaru used the continuous-flow electric method with a preheater partially inclosed in the furnace surrounding the calorimeter. The rate of flow of the ammonia vapor was varied by a factor of three. The main uncertainty in their results lies in the evaluation of the heat leakage. Two experimental arrangements were employed which differed only in the shielding of the electric heater. They state that the measurements with arrangement $\mathrm{A}$ constitute an absolute determination of $C_{\mathrm{p}}$, while those with arrangement $\mathrm{B}$ constitute only

19 Wärmetabellen, Friedr. Vieweg. \& Sohn, Braunschweig: 1919. 
relative determinations. The heat leakage with arrangement $A$, amounting from 10 to 25 per cent of the heat added electrically, was found to be independent of the rate of flow and was evaluated by the method of extrapolation to infinite flow. With arrangement $B$ the heat leakage was found to be a function of the rate of flow and its magnitude was inferred from other experiments on air and carbon dioxide.

A comparison of the experimental determinations of $C_{\mathrm{p}}$ at one atmosphere pressure is shown graphically in Figure 11. It seems probable that the extrapolation of the present authors' empirical equation leads to high values of the specific heat at high temperatures. It is evident that the results of Nernst and of Haber and Tamaru are somewhat inconsistent with the present results and do not indicate

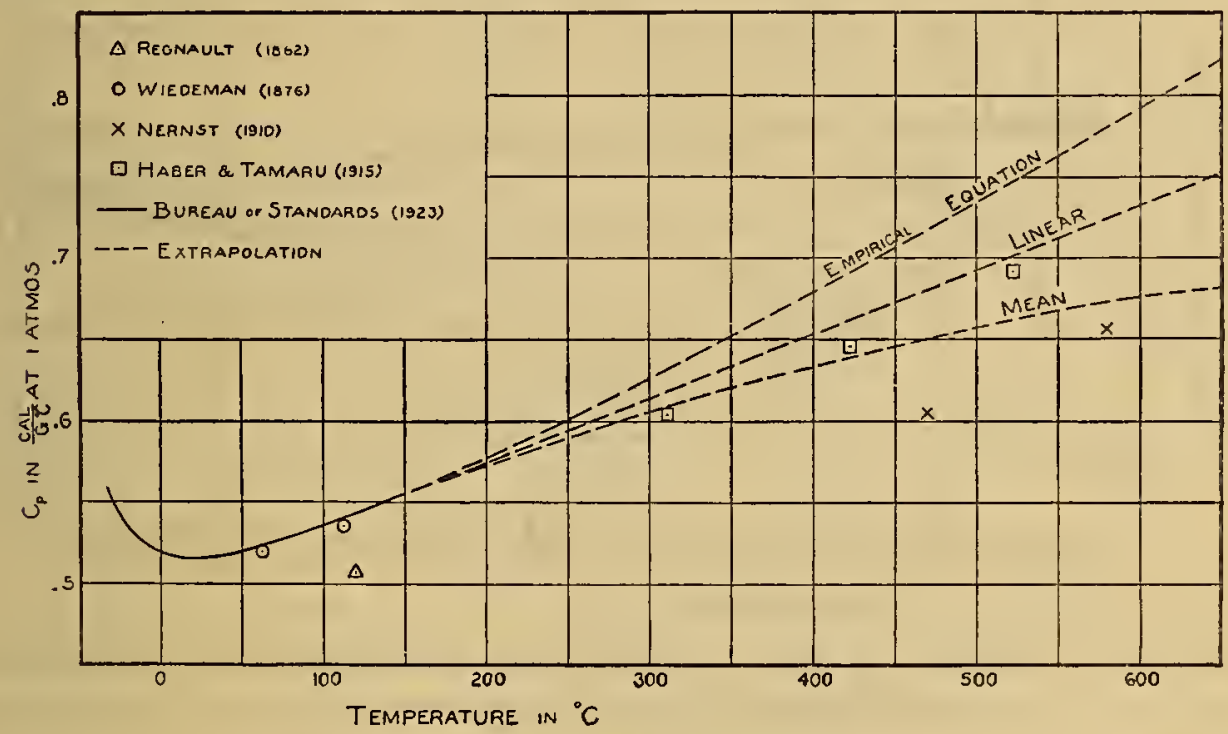

FIG. 11.-Comparison of experimental determinations of specific heat of ammonia vapor at one atmosphere

with certainty the trend of the curve at high temperatures. The assumption of a constant error of a few per cent in the results of Haber and Tamaru suggests the linear extrapolation shown in Figure 11. The lower curve represents the mean of the two sets of results.

With experimental determinations of $C_{\mathrm{p}}$ at one atmosphere pressure available, it is possible to derive values of $C_{\mathrm{p}}$ at higher pressures by means of an "equation of state." Goodenough and Mosher, ${ }^{20}$ and Keyes and Brownlee, ${ }^{21}$ have published, in their respective ammonia tables, the results of such a computation. Their equations, although widely different in form and based upon different data, give values of the specific volume of the superheated vapor which agree with the

${ }^{20}$ Univ. of III. Exp. Station, Bulletin No. 66; 1913.

2t Thermodynamic Properties of Ammonia, John Wiley \& Sons; 1916. 
values given in the Bureau of Standards tables ${ }^{22}$ to about 1 or 2 per cent, in general. It is interesting, therefore, to note the comparison of their computed values of $C_{\mathbf{p}}$ with the results of the present experiments as shown in Figure 12. For convenience in showing this comparison graphically, the values resulting from the present experiments are represented by the zero line and the curves show the percentage deviation of the computed values at various pressures.

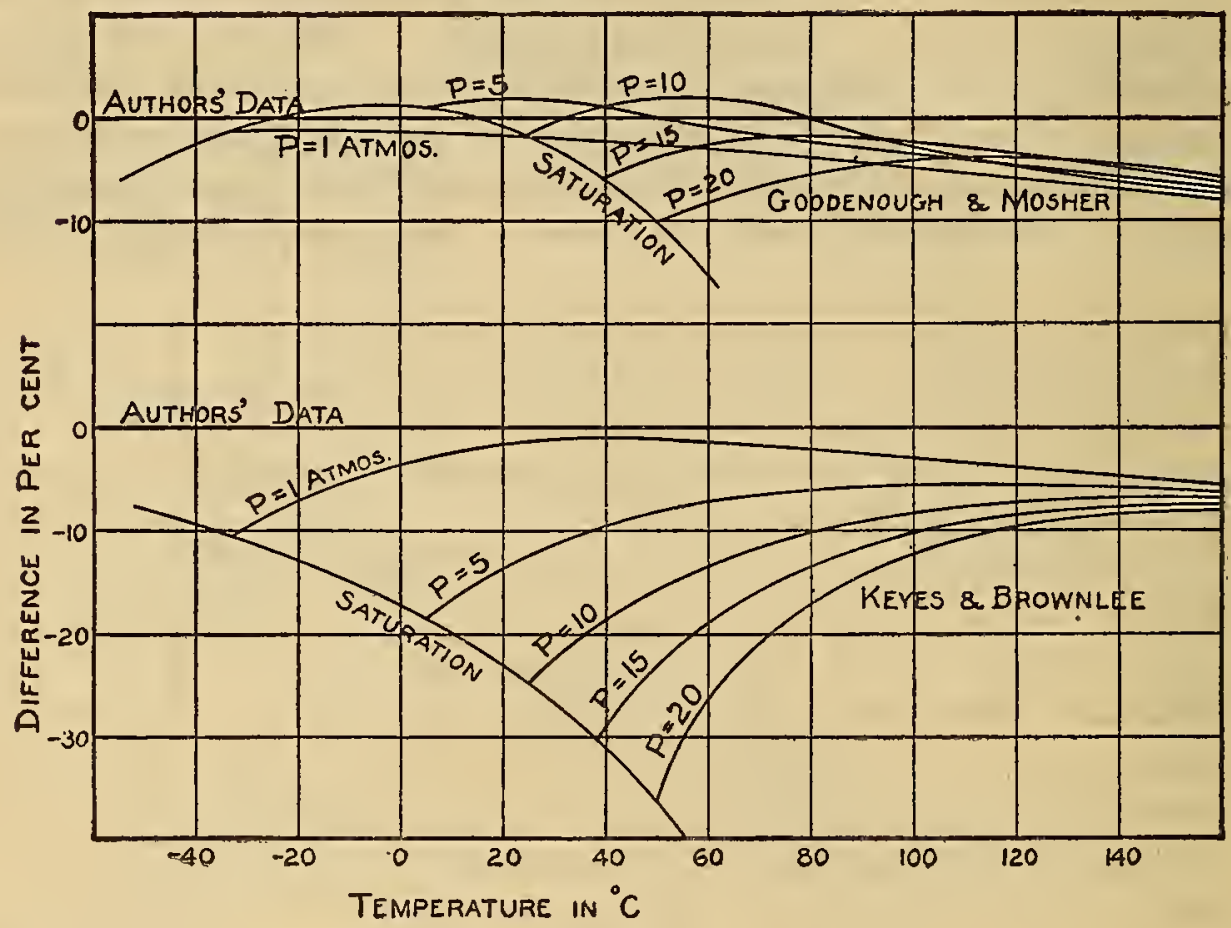

Fig. 12.-Comparison of values of specific heat of ammonia vapor from earlier formulations with authors' experimental data

\section{SUMMARY}

(1) A series of measurements of the specific heat of superheated ammonia vapor at constant pressure were made to supply data for tables of thermodynamic properties of ammonia suitable for use in refrigerating engineering.

(2) The continuous-flow electric method was employed, which consists of observing the rise in temperature produced by a measured electric power added as heat to a steady stream of vapor flowing at a measured rate. The advantages of this method for measurements of the specific heat of gases are pointed out. An abridged description is given of the flow calorimeter, which was especially designed and constructed for making these measurements on ammonia. The design is appropriate for similar measurements on other vapors and gases at.

22 Tables of Thermodynamic Properties of Ammonia, B. S. Circular No. 142, 1st edition; 1923. 
temperatures below $150^{\circ} \mathrm{C}$. and pressures below 100 atmospheres. Several features of this calorimeter are: Utility over a wide range of temperature and pressure; small thermal leakage; small size and heat capacity, requiring, therefore, only small samples of the purified material and a short time in coming to a steady state. A brief description is given of the thermoregulated baths, the temperature-control unit used for each bath, and the special devices used for regulating the rate of flow of the vapor. Many other details are described which have a bearing on the accuracy of the results obtained.

An expression is developed for the specific heat at constant pressure for a definite temperature and pressure which contains the three principal quantities observed-temperature rise, power input, and rate of flow-and, in addition, correction terms for thermal leakage, pressure drop, and the variation of the specific heat with temperature.

(4) The process of purification of the ammonia used in the measurements is described briefly. Tests made upon several samples, which were purified by this process, indicated the presence of less than 0.01 per cent by weight of water and less than 0.01 per cent by volume of noncondensing gases in the vapor phase.

(5) The procedures followed in the experiments and in the calibration of the instruments are described in detail. The correction for thermal leakage rarely exceeded 0.2 per cent of the heat supplied electrically in any experiment. The crucial test of the proper corrections for thermal leakage and pressure drop is the constancy of the final result with various rates of flow of the vapor.

(6) The results of 108 complete experiments serve to establish the value of the specific heat at 35 points in the temperature range -15 to $+150^{\circ}$ C. and the pressure range 0.5 to 20 atmospheres. Several determinations of the Joule-Thomson coefficient were made in order to evaluate the correction for pressure drop in the specific heat experiments.

(7) An empirical equation of the form $C_{\mathrm{p}}=f(p, \theta)$ was chosen to represent the experimental results within the range covered by the experiments.

(8) Values of $C_{\mathrm{p}}$ computed from the empirical equation agree with the experimental values within 0.3 per cent in all cases. The average agreement is 0.07 per cent.

(9) Previous measurements of the specific heat of ammonia vapor are briefly reviewed and tabulated.

(10) A table containing values of $C_{\mathrm{p}}$ at convenient intervals of pressure and temperature is appended. 


\section{APPENDIX: TABLE OF $C_{p}$}

TABLE 9.-Specific heat of ammonia vapor at constant pressure

[Calories per gram per degree centigrade]

\begin{tabular}{|c|c|c|c|c|c|c|c|c|c|c|c|}
\hline \multirow{2}{*}{$\begin{array}{l}\text { Tempera- } \\
\text { ture }{ }^{\circ} \mathrm{C} \text {. }\end{array}$} & \multicolumn{11}{|c|}{ Pressure in atmospheres. (Saturation temperature in italics.) } \\
\hline & 0 & $\begin{array}{c}1 \\
-33.95^{\circ}\end{array}$ & $\mid \begin{array}{c}2 \\
-18.57^{\circ}\end{array}$ & $\begin{array}{c}3 \\
-8.91^{\circ}\end{array}$ & $\begin{array}{c}4 \\
-1.54^{\circ}\end{array}$ & $\begin{array}{r}5 \\
+4.50^{\circ}\end{array}$ & $9.67^{\circ}$ & $14.21^{\circ}$ & $\begin{array}{c}8 \\
18.27^{\circ}\end{array}$ & $21.96^{\circ}$ & $\begin{array}{c}10 \\
25.34^{\circ}\end{array}$ \\
\hline Sat. & & 0.5593 & 0.5935 & 0.6214 & 0.6457 & 0.6676 & 0.6877 & 0.7065 & 0.7242 & 0.7411 & 0.7575 \\
\hline $\begin{array}{l}-30 \\
-20 \\
-10\end{array}$ & $\begin{array}{r}0.4829 \\
.4856 \\
.4885\end{array}$ & $\begin{array}{l}.5513 \\
.5344 \\
.5247\end{array}$ & .5704 & & & & & & & & \\
\hline 0 & . 4917 & .5194 & .5532 & . 5931 & . 6392 & & & & & & \\
\hline $\begin{array}{l}10 \\
20\end{array}$ & .4950 & & .5426 & .5724 & .6062 & .6440 & .6860 & & 74 & & 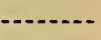 \\
\hline 30 & .59021 & .0101 & .0330 & .5510 & $\begin{array}{l}.0848 \\
.5708\end{array}$ & .5130 & $\begin{array}{l}.6438 \\
.6158\end{array}$ & .6410 & $\begin{array}{l}.6682 \\
.6682\end{array}$ & .6974 & .7289 \\
\hline 40 & .5058 & .5181 & .5315 & .5461 & .5619 & .5788 & .5970 & .6164 & .6371 & .6592 & .6826 \\
\hline 50 & . 5097 & .5201 & . 5313 & .5434 & .5562 & .5699 & .5843 & . 5997 & .6158 & .6329 & .6510 \\
\hline 60 & .5137 & .5227 & .5322 & .5423 & .5529 & .5641 & .5759 & .5883 & .6012 & .6148 & .6290 \\
\hline $\begin{array}{l}70 \\
80\end{array}$ & $\begin{array}{r}.5178 \\
5920\end{array}$ & .5256 & $\begin{array}{r}.5338 \\
-5350\end{array}$ & $\begin{array}{r}.5423 \\
.5432\end{array}$ & .5513 & .5607 & .5704 & .5806 & $\begin{array}{r}.5912 \\
5844\end{array}$ & . 6022 & .6136 \\
\hline 90 & .02202 & .0288 & .0309 & .5432 & .0510 & $\begin{array}{l}.0089 \\
.5583\end{array}$ & .5654 & $\begin{array}{l}.0700 \\
.5726\end{array}$ & $\begin{array}{l}.5844 \\
.5800\end{array}$ & $\begin{array}{l}.5930 \\
.5877\end{array}$ &. .59295 \\
\hline 100 & . 5306 & .5359 & .5414 & .5470 & .5528 & .5587 & .5648 & .5710 & .5774 & .5839 & . $590 \overline{0}$ \\
\hline 110 & . 5350 & .5397 & .5446 & .5496 & 5547 & .5598 & .5651 & .5705 & .5760 & .5817 & .5874 \\
\hline 120 & . 5394 & . 5437 & 5481 & 5525 & 5570 & 5616 & .5662 & .5710 & .57 & .5807 & .5856 \\
\hline 130 & .5440 & .5478 & 5517 & 5557 & 5597 & .5637 & .5679 & .5721 & .5763 & . 5806 & $\begin{array}{r}.5850 \\
.5850\end{array}$ \\
\hline & & & & & & & & & & & \\
\hline 150 & . 5532 & .5563 & . 5595 & .5627 & . 5660 & .5692 & . 5725 & .5759 & . 5792 & .5826 & .5860 \\
\hline $\begin{array}{l}\text { Tempera- } \\
\text { ture }{ }^{\circ} \mathrm{C} \text {. }\end{array}$ & $\begin{array}{c}10 \\
25.34^{\circ}\end{array}$ & $\begin{array}{c}11 \\
28.47^{\circ}\end{array}$ & $\begin{array}{c}12 \\
81.40^{\circ}\end{array}$ & $\begin{array}{c}13 \\
34.15^{\circ}\end{array}$ & $\begin{array}{l}14 \\
86.74^{\circ}\end{array}$ & $\begin{array}{c}15 \\
\$ 9.19^{\circ}\end{array}$ & $\begin{array}{c}16 \\
41.52^{\circ}\end{array}$ & $\begin{array}{l}17 \\
49.75^{\circ}\end{array}$ & $\begin{array}{c}18 \\
45.88^{\circ}\end{array}$ & $\begin{array}{c}19 \\
47.92^{\circ}\end{array}$ & $\begin{array}{c}20 \\
49.89^{\circ}\end{array}$ \\
\hline Sat. & 0.7575 & 0.7734 & 0.7890 & 0.8044 & 0.8199 & 0.8355 & 0.8513 & 0.8674 & 0.8839 & 0.9009 & 0.9186 \\
\hline $\begin{array}{l}30 \\
40\end{array}$ & .7289 & .7629 & & & & & & & & & \\
\hline 40 & .6826 & .7077 & .7346 & .7634 & . 7946 & .8286 & & & & & \\
\hline 50 & .6510 & .6700 & . 6902 & .7117 & .7345 & .7590 & .7854 & .8140 & .8452 & .8795 & .9173 \\
\hline 60 & .6290 & . 6439 & . 6595 & .6759 & . 6932 & .7115 & .7310 & .7518 & & .7982 & .8244 \\
\hline 70 & .6136 & .6255 & .6379 & .6508 & .6643 & .6784 & .6933 & .7090 & .72 & .7432 & .7621 \\
\hline 00 & & 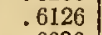 & .6227 & & .6438 & .6550 & .6667 & & & .7051 & .71 \\
\hline 90 & .5955 & .6036 & .6119 & . 6204 & .6292 & .6383 & .6477 & .6574 & .6675 & .6781 & .6890 \\
\hline 100 & . 5905 & . 5974 & .6043 & .6115 & .6188 & .6263 & .6341 & .6420 & .6502 & .6587 & .6674 \\
\hline 110 & .5874 & .5932 & .5992 & 60 & .61 & .6178 & .62 & .63 & & & .6518 \\
\hline 120 & .5856 & .5907 & .5958 & .6011 & .6064 & .6118 & .6173 & .6229 & .628 & .6345 & .8404 \\
\hline & & 5894 & .5939 & .5984 & .6030 & .6077 & .6124 & .6172 & .6222 & .6271 & .6322 \\
\hline 140 & .5852 & .5891 & .5930 & .5970 & .6010 & .6051 & .6093 & .6134 & .6177 & .6220 & .6263 \\
\hline 150 & . 5860 & .5895 & .5930 & .5965 & .6001 & .6037 & .6073 & .6110 & .6147 & .6185 & .6223 \\
\hline
\end{tabular}

Washington, July 21, 1924. 